\title{
Investigation of Influence Factors of Wind-Induced Buffeting Response of a Six-Tower Cable-Stayed Bridge
}

\author{
Zhi-Qiang Zhang, ${ }^{1}$ You-Liang Ding, ${ }^{1}$ and Fang-Fang Geng ${ }^{2}$ \\ ${ }^{1}$ Key Laboratory of Concrete and Prestressed Concrete Structures of Ministry of Education, \\ Southeast University, Nanjing 210096, China \\ ${ }^{2}$ Architectural Engineering Institute, Nanjing Institute of Technology, Nanjing 211167, China
}

Correspondence should be addressed to You-Liang Ding; civilchina@hotmail.com

Received 1 February 2015; Revised 7 June 2015; Accepted 15 September 2015

Academic Editor: Gyuhae Park

\begin{abstract}
Copyright (C) 2016 Zhi-Qiang Zhang et al. This is an open access article distributed under the Creative Commons Attribution License, which permits unrestricted use, distribution, and reproduction in any medium, provided the original work is properly cited.

This paper presents an investigation of the wind-induced buffeting responses of the Jiashao Bridge, the longest multispan cablestayed bridge in the world. A three-dimensional finite element model for the Jiashao Bridge is established using the commercial software package ANSYS and a 3D fluctuating wind field is simulated for both bridge deck and towers. A time-domain procedure for analyzing buffeting responses of the bridge is implemented in ANSYS with the aeroelastic effect included. The characteristics of buffeting responses of the six-tower cable-stayed bridge are studied in some detail, focusing on the effects including the difference in the longitudinal stiffness between the side towers and central towers, partially longitudinal constraints between the bridge deck and part of bridge towers, self-excited aerodynamic forces, and the rigid hinge installed in the middle of the bridge deck. The analytical results can provide valuable references for wind-resistant design of multispan cable-stayed bridges in the future.
\end{abstract}

\section{Introduction}

For long-span cable-stayed bridges, the multispan cablestayed bridges with three or more towers have been a recent design trend $[1,2]$. Typical examples of this bridge type are the Millau Viaduct Bridge in France, the Maracaibo Bridge in Venezuela, the Rion-Antirion Bridge in Greece, the Mezcala Bridge in Mexico, the Dongting Lake Bridge in China, and the Ting Kau Bridge in Hong Kong [1-4]. The longest multispan cable-stayed bridge in the world is Jiashao Bridge in China, which is a six-tower cable-stayed bridge with the total length of $2680 \mathrm{~m}$. Compared with a conventional threespan cable-stayed bridge with two towers, large temperatureinduced deformation in the long bridge deck is one of the major problems in the design of multispan cable-stayed bridges. The commonly used structural measures to reduce the temperature effects include two aspects: (i) partially longitudinal constraints between the bridge deck and part of bridge towers such as the Millau Viaduct Bridge in France and the Jiashao Bridge in China and (ii) rigid hinge to release the temperature-induced deformation in the bridge deck such as the Jiashao Bridge in China. The aforementioned structural measures can improve the static performance of the multispan cable-stayed bridge under temperature action. However, studies of the wind-resistant performance of the multispan cable-stayed bridge using the partially longitudinal constraints and rigid hinge are meager. In addition, it is also necessary to investigate some unique features of the aerodynamic behavior of the multispan cable-stayed bridge considering the insufficient longitudinal stiffness of the central towers and self-excited force effect.

To date, an amount of research work had been done on investigating the buffeting response analysis of long-span bridges. The buffeting of long-span bridges is a type of vibration motion induced by wind turbulence. The buffeting responses are related not only to the wind field property and structural dynamic properties but also to the geometrical shape of bridge sections and the interaction between wind and structural motions $[5,6]$. With the increase of the bridge length, buffeting analysis for slender bridge structures 


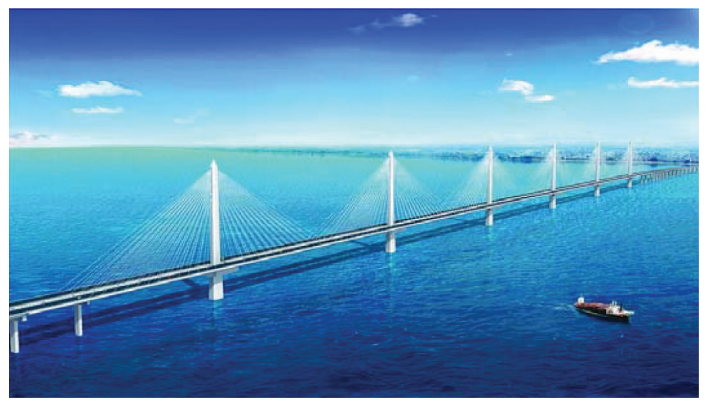

(a) View of Jiashao Bridge

Tower number 1 Tower number 2 Tower number 3

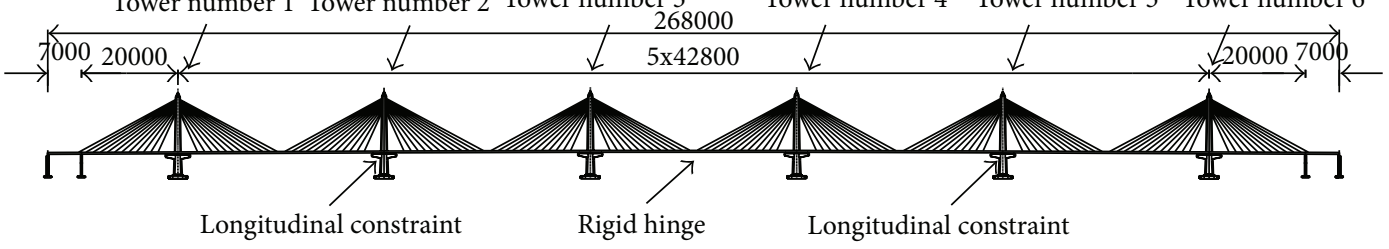

(b) Elevation of Jiashao Bridge (unit: $\mathrm{cm}$ )

FIgURE 1: Jiashao Bridge.

under strong wind actions becomes increasingly important. Buffeting analysis can be carried out in either frequency domain or time domain. Many early investigations were focused on the frequency domain analysis methods, in which statistical quantities in terms of spectral density and variance of structural response are obtained [7]. Compared with the frequency domain analysis methods, time-domain assessment of the buffeting response is convenient, since structural and aerodynamic nonlinearities may be taken more easily into account in the time domain. Hence, investigations of time-domain buffeting analysis have been done by several researchers in recent years $[5,8-13]$. These investigations conducted into the application of time-domain buffeting analysis of long-span bridges provide valuable references for the wind-induced buffeting responses of the multispan cablestayed bridges in the present study.

This paper investigates the wind-induced buffeting responses of the Jiashao Bridge, the longest multispan cablestayed bridge in the world. The specific objectives of this study are to (i) perform the time-domain buffeting responses of the multispan cable-stayed bridge implemented in ANSYS with the aeroelastic effect included; (ii) investigate the distribution characteristics of buffeting responses of the bridge deck and bridge towers; and (iii) investigate the effects including the difference in the longitudinal stiffness between the side towers and central towers, partially longitudinal constraints between the bridge deck and part of bridge towers, selfexcited aerodynamic forces, and the rigid hinge installed in the middle of the bridge deck on the buffeting responses of the multispan cable-stayed bridge.

\section{Bridge Description}

The subject of this study is Jiashao Bridge shown in Figure 1(a), which is a six-tower cable-stayed bridge that

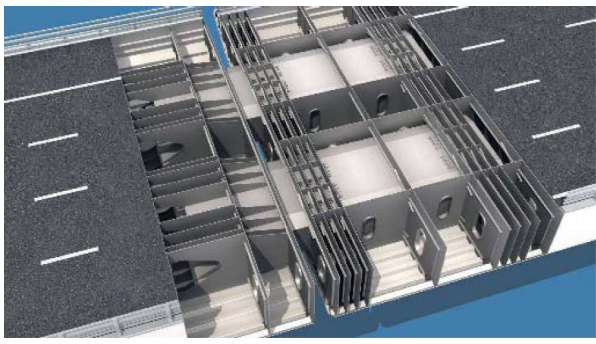

FIGURE 2: "Drawer-type" rigid hinge.

crosses the Hangzhou Bay, along the highway between Jiaxing and Shaoxing in China. The total length of the bridge is $2680 m$ with the span arrangement of $70 m+200 m+5 \times$ $428 \mathrm{~m}+200 \mathrm{~m}+70 \mathrm{~m}$, which is the longest multispan cablestayed bridge in the world. Figure 1(b) shows the schematic elevation view of the Jiashao Bridge. In order to overcome the problem of large temperature-induced longitudinal deformation in the bridge deck, two important structural measures are applied in the design of Jiashao Bridge as shown in Figure 1(b): (i) The "drawer-type" rigid hinge shown in Figure 2 is installed in the midspan of the bridge deck. The rigid hinge can automatically adapt to changes in longitudinal deformation due to ambient temperature variations and meet the requirements of loading capacity under normal traffic conditions. (ii) The partially longitudinal constraint system is applied in the design of Jiashao Bridge. As shown in Figure 1(b), the longitudinal constraints are applied to restrict the bridge deck from moving in the longitudinal direction at bridge towers number 2 and number 5, respectively. And there have been no longitudinal constraints between the bridge deck and other bridge towers. The role of such partially longitudinal constraint system is to reduce the temperatureinduced longitudinal deformation in the bridge deck. 


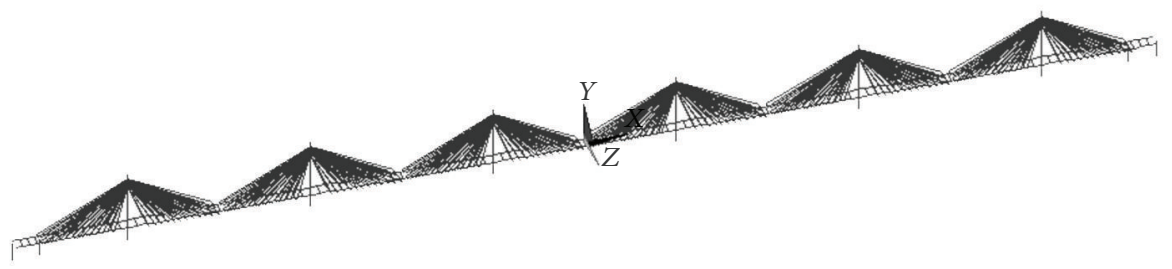

FIGURE 3: Finite element model of Jiashao Bridge.

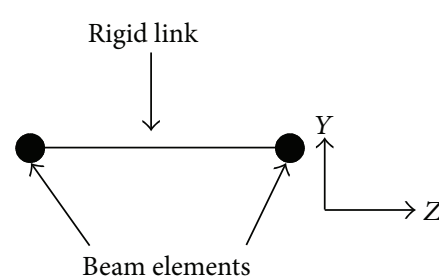

(a) Rigid links connecting two steel box girders

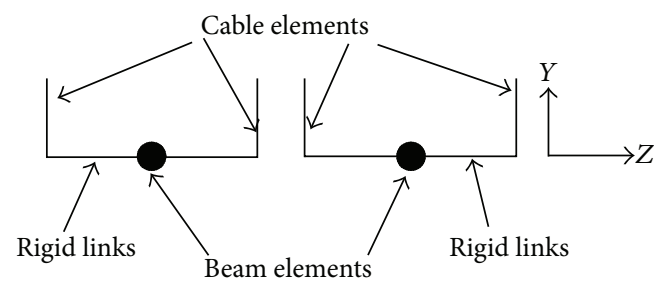

(b) Rigid links connecting stay cables

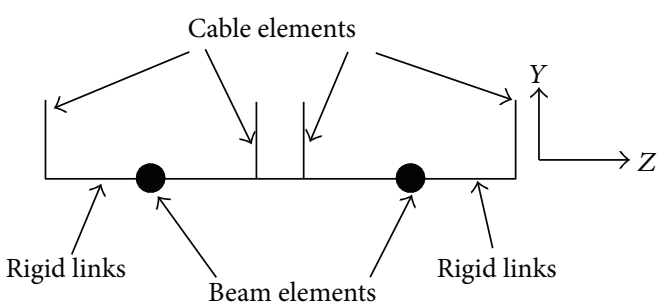

(c) Rigid links simultaneously connecting two steel box girders and stay cables

FIGURE 4: Detailed finite element modeling for rigid links.

\section{Dynamic Finite Element Model}

A three-dimensional finite element model of the Jiashao Bridge has been developed by use of the commercial software package ANSYS (ANSYS 2009). The finite element model involves 1402 nodes and 1872 elements, as shown in Figure 3. In this model, a double-girder model is used to simulate the bridge deck system when conducting dynamic analysis. The two steel box girders are modeled as Timoshenko's beam elements with 6 degrees of freedom (DOFs) at each node, which account for transverse shear deformation, biaxial bending, and axial strain. And the crossbeams connecting two steel box girders are modeled as rigid links at $30 \mathrm{~m}$ intervals as shown in Figure 4(a). The bridge towers and piers are also modeled as Timoshenko's beam elements. A 2-node truss element is used to simulate the stay cables, which accounts for only tension and no compression based on the real condition. Considering the geometric stiffness of stay cables under dead loading, the Ernst equivalent elastic modulus for stay cables is adopted [14]. Rigid links at $15 \mathrm{~m}$ intervals are used to connect the cables in four planes to the girders as shown in Figure 4(b). Figure 4(c) further shows the case of rigid links simultaneously connecting two steel box girders and four stay cables.

The detailed finite element modeling for the constraints between the girders and towers (piers) is described as follows: (i) Modeling of constraints between the girders and towers: as shown in Figure 5(a), constraints are applied to restrict the deck from moving in the $X, Y$, and $Z$ directions at bridge towers number 2 and number 5. Thus, the constraint equations of DOFs for the nodes N1 $\sim N 3$ shown in Figure 5(a) can be defined as $U X(N 1)=U X(N 2)=U X(N 3), U Y(N 1)=$ $U Y(N 2)=U Y(N 3)$, and $U Z(N 1)=U Z(N 2)=$ $U Z(N 3)$. It should be noted that, for other towers number 1 , number 3 , number 4 , and number 6 , constraints are applied to restrict the deck from moving in the $Y$ and $Z$ directions. Thus, the constraint equations of DOFs for the nodes $N 1 \sim N 3$ can be defined as $U Y(N 1)=U Y(N 2)=U Y(N 3)$ and $U Z(N 1)=U Z(N 2)=U Z(N 3)$.

(ii) Modeling of constraints between the girders and piers in each side span: as shown in Figure 5(b), constraints are applied to restrict the motion of bridge deck at all bridge piers including auxiliary pier and end pier to allow only longitudinal displacement $X$ and rotations about the $Y$ and $Z$ axes. Thus, the constraint equations of DOFs for the nodes N1 N6 shown in Figure 5(b) can be defined as $U Y(N 1)=U Y(N 2)=$ $U Y(N 3), U Y(N 4)=U Y(N 5)=U Y(N 6), U Z(N 1)=$ $U Z(N 2)=U Z(N 3), U Z(N 4)=U Z(N 5)=U Z(N 6)$, 


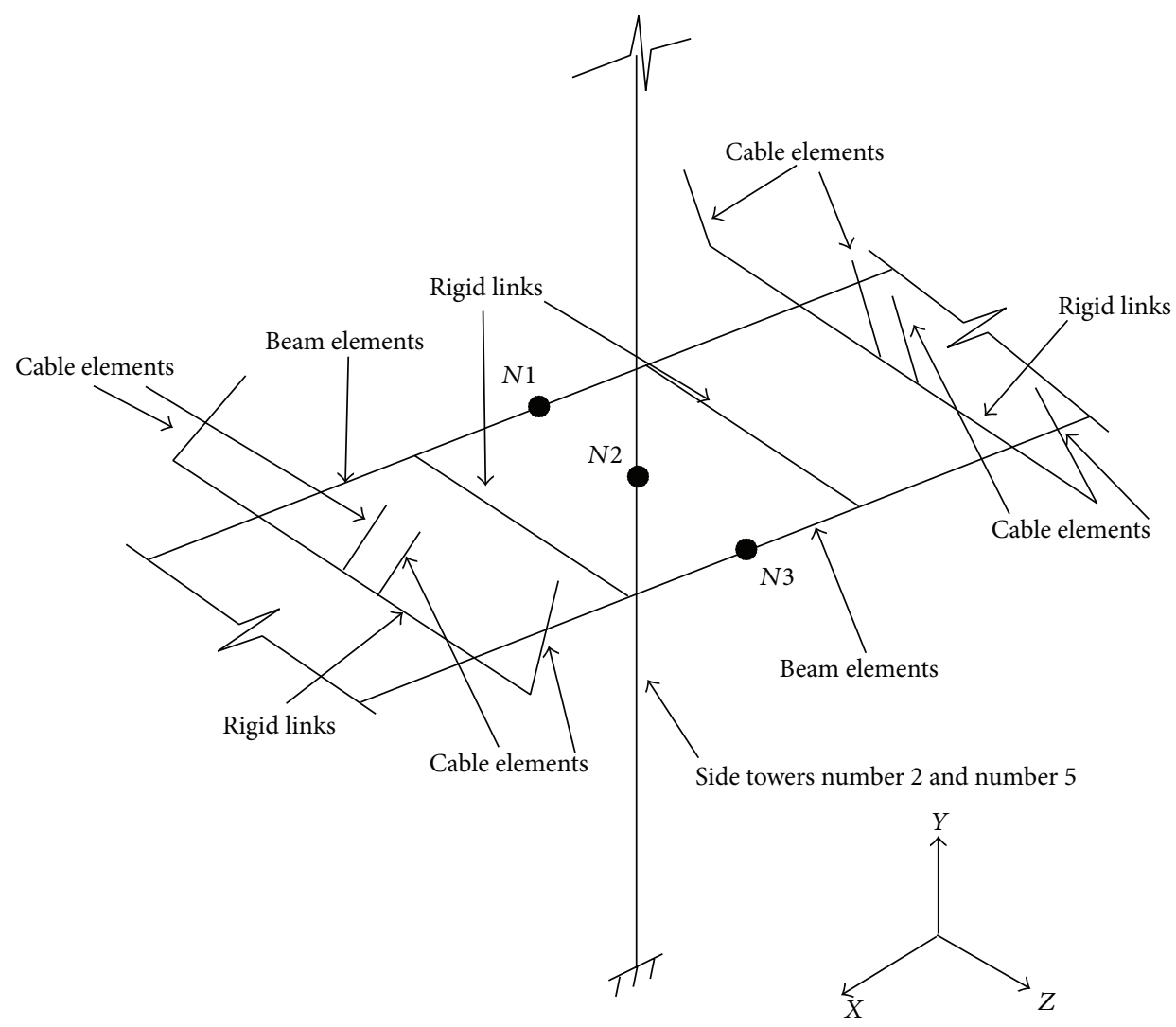

(a) Constraints between the girders and side towers number 2 and number 5

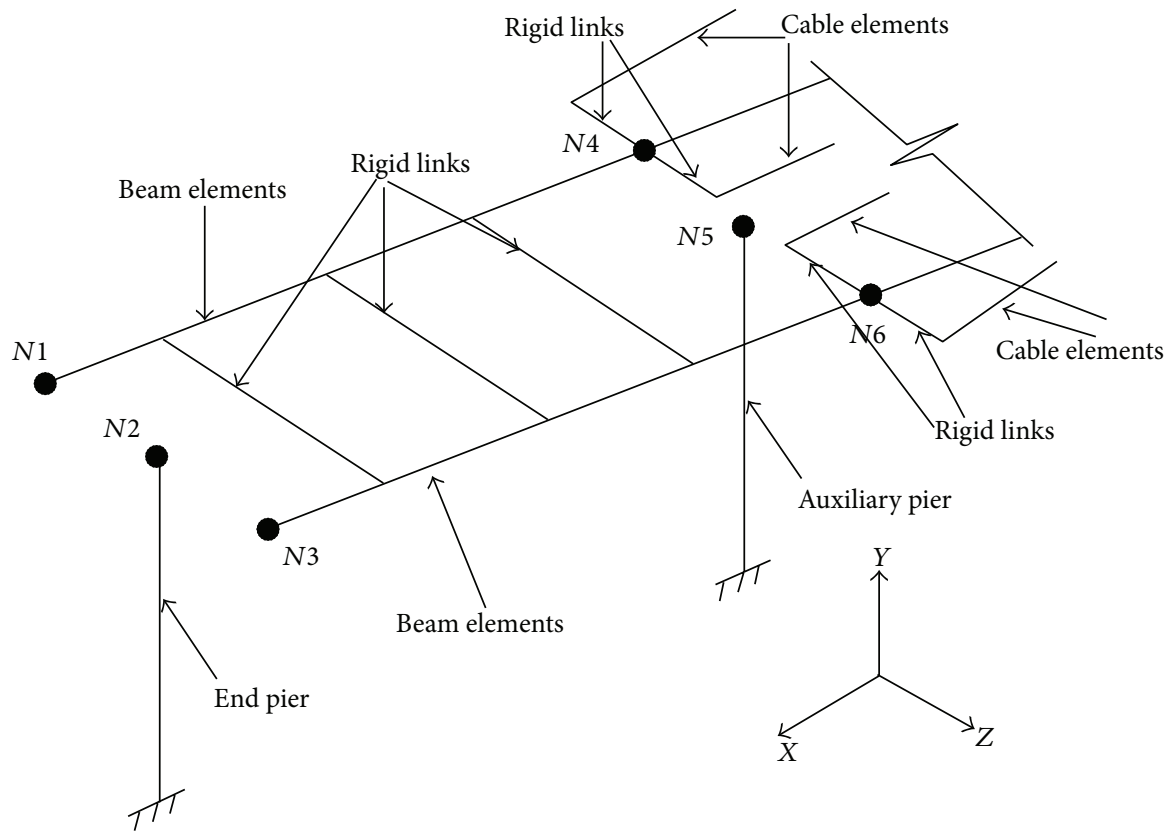

(b) Auxiliary pier and end pier in each side span

FIGURE 5: Detailed finite element modeling for the constraints between the girders and towers (piers).

$\operatorname{ROTX}(N 1)=\operatorname{ROTX}(N 2)=\operatorname{ROTX}(N 3)$, and $\operatorname{ROTX}(N 4)=\operatorname{ROT} X(N 5)=\operatorname{ROT} X(N 6)$.

Considering that the structural dynamic properties including modal frequencies and mode shapes form the basis of buffeting response analysis of the bridge, it is especially desirable to understand the dynamic characteristics of the bridge. Hence, the modal analysis of the Jiashao Bridge is conducted with the developed finite element model. The static equilibrium state of the bridge, which is the initial 
TABLE 1: Vibration modes of finite element model of Jiashao Bridge.

\begin{tabular}{|c|c|c|c|c|}
\hline $\begin{array}{l}\text { Mode } \\
\text { number }\end{array}$ & $\begin{array}{c}\text { Calculated } \\
\text { frequency } f / \mathrm{Hz}\end{array}$ & $\begin{array}{c}\text { Identified frequency } \\
f_{0} / \mathrm{Hz}\end{array}$ & $\Delta f(\%)$ & Description \\
\hline 1 & 0.2274 & 0.2371 & 4.0949 & $\begin{array}{l}\text { 1st symmetric bending of bridge deck in } Y \text { direction }+ \text { symmetric } \\
\text { bending of bridge tower in } X \text { direction }\end{array}$ \\
\hline 2 & 0.2615 & 0.2567 & 1.8814 & $\begin{array}{l}\text { 1st antisymmetric bending of bridge deck in } Y \text { direction }+ \\
\text { antisymmetric bending of bridge tower in } X \text { direction }\end{array}$ \\
\hline 3 & 0.2894 & 0.2730 & 6.0160 & 1st symmetric bending of bridge tower in $Z$ direction \\
\hline 4 & 0.2907 & 0.2780 & 4.5604 & 1st antisymmetric bending of bridge tower in $Z$ direction \\
\hline 5 & 0.2928 & 0.2796 & 4.7231 & 2nd symmetric bending of bridge tower in $Z$ direction \\
\hline 6 & 0.2950 & 0.2792 & 5.6412 & 2nd antisymmetric bending of bridge tower in $Z$ direction \\
\hline 7 & 0.2965 & - & - & 3rd symmetric bending of bridge tower in $Z$ direction \\
\hline 8 & 0.2970 & - & - & 3rd antisymmetric bending of bridge tower in $Z$ direction \\
\hline 9 & 0.3085 & 0.3181 & 3.0158 & $\begin{array}{l}\text { 2nd symmetric bending of bridge deck in } Y \text { direction }+ \text { symmetric } \\
\text { bending of bridge tower in } X \text { direction }\end{array}$ \\
\hline 10 & 0.3618 & 0.3786 & 4.4456 & $\begin{array}{l}\text { 2nd antisymmetric bending of bridge deck in } Y \text { direction }+ \\
\text { antisymmetric bending of bridge tower in } X \text { direction }\end{array}$ \\
\hline 21 & 0.7087 & 0.6882 & 2.9752 & $\begin{array}{l}\text { 1st symmetric lateral bending of bridge deck in } Z \text { direction }+ \\
\text { symmetric lateral bending of bridge tower in } Z \text { direction }\end{array}$ \\
\hline 33 & 0.8956 & 0.9467 & 5.3985 & $\begin{array}{l}\text { 1st antisymmetric bending of bridge deck in } Z \text { direction }+ \\
\text { antisymmetric bending of bridge tower in } Z \text { direction }\end{array}$ \\
\hline 43 & 1.1361 & 1.1948 & 4.9131 & 1st symmetric torsion of bridge deck \\
\hline 44 & 1.1389 & 1.2007 & 5.1478 & 2nd symmetric torsion of bridge deck \\
\hline 45 & 1.1391 & - & - & 3rd symmetric torsion of bridge deck \\
\hline
\end{tabular}

Note: $\Delta f=\left|f-f_{0}\right| \times 100 \% / f_{0}$.

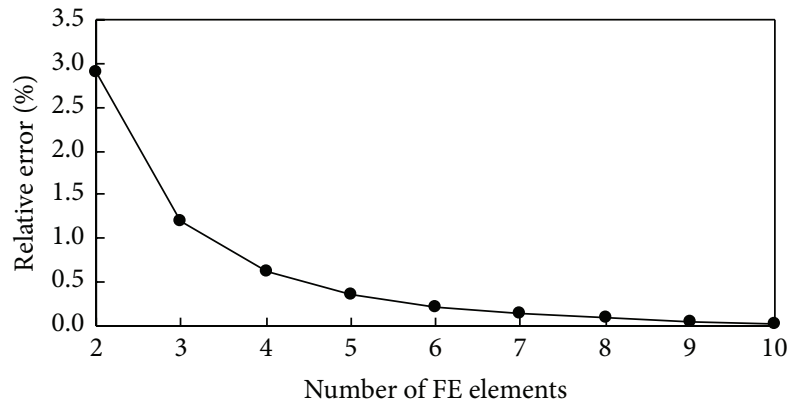

(a) The first symmetric bending of bridge tower in $X$ direction

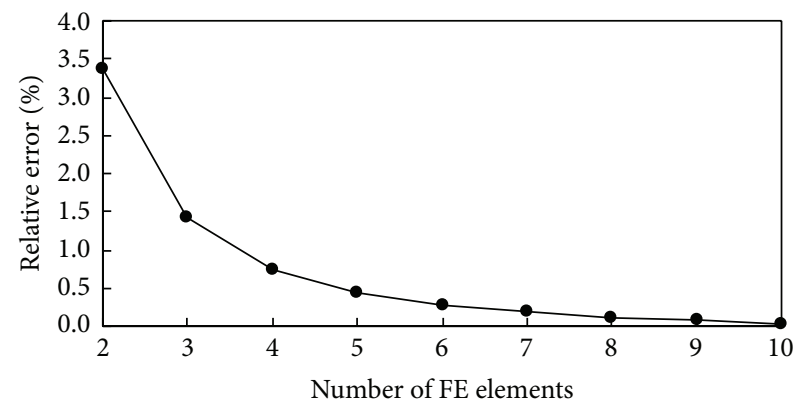

(b) The first symmetric bending of bridge tower in $Z$ direction

FIGURE 6: Relative errors of model frequencies with regard to various numbers of FE elements of bridge towers.

configuration for modal analysis, is achieved by geometrically nonlinear analysis of the bridge under dead loadings. The LANCZOS eigenvalue solver is adopted for modal analysis. It should be noted that, before implementing main FE modal analysis, the inaccuracy in FE modeling due to model meshing error should be eliminated considering mesh dependency. The mesh size of the FE model is determined by the convergence test of the mesh size and the analysis results reveal that the modeling meshing error caused by the discretization of the steel box girder can be ignored when the steel box girder is meshed according to the locations of the node of stay cables. And the number of FE elements of bridge towers is also determined using the convergence test. Figure 6 shows the relative errors of model frequencies of the first symmetric bending of bridge tower in $X$ direction and $Z$ directions with regard to various numbers of $\mathrm{FE}$ elements of bridge towers, where the model frequencies with the 10 elements are assumed to be reference values. It can be seen that the modeling meshing error is reduced significantly with the increase of the number of FE elements. When the number of FE elements of bridge towers is larger than 8 , the relative error is smaller than $0.05 \%$. Thus, 8 elements of bridge towers are used in the FE model.

Main vibrations modes of finite element model are listed in Table 1 and part of them are shown in Figure 7. In order to verify the representing capabilities of the bridge dynamic behavior using the developed finite element model, Table 1 further shows the comparison of the calculated frequencies of the finite element model and experimentally identified frequencies using the ambient vibration test. It is clearly shown that a good agreement between calculated and identified frequencies of the Jiashao Bridge is obtained. Thus, the developed finite element model will serve as a basis for nonlinear buffeting analysis of the bridge.

The modal analysis results reveal the following dynamic properties of the bridge: (i) The floating vibration mode in 


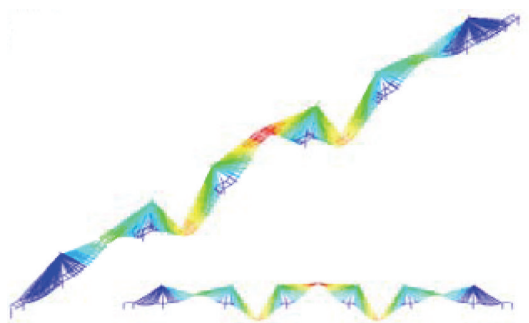

(a) 1st symmetric bending of bridge deck in $Y$ direction + symmetric bending of bridge tower in $X$ direction

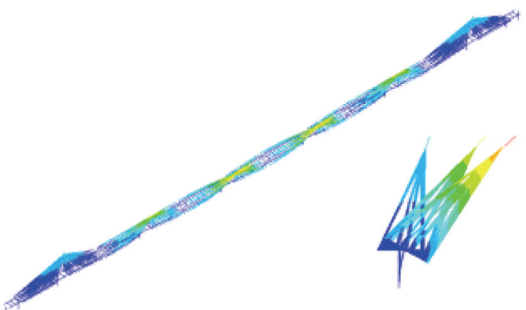

(c) 1st symmetric bending of bridge tower in $Z$ direction

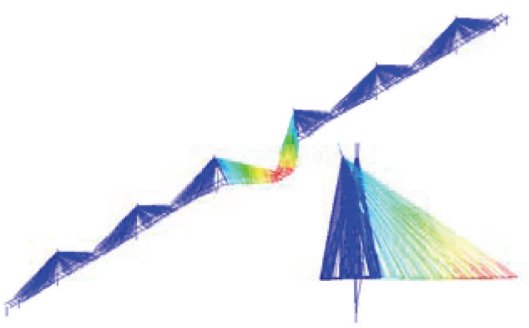

(e) 1st symmetric bending of bridge deck in $Z$ direction + symmetric bending of bridge tower in $Z$ direction

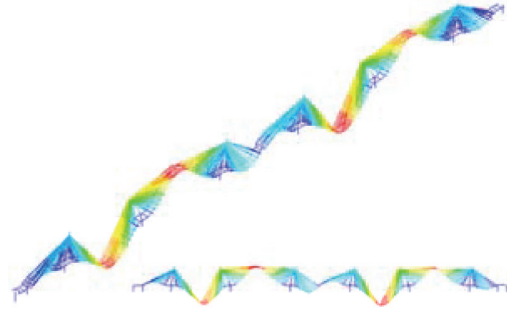

(b) 1st antisymmetric bending of bridge deck in $Y$ direction + antisymmetric bending of bridge tower in $X$ direction

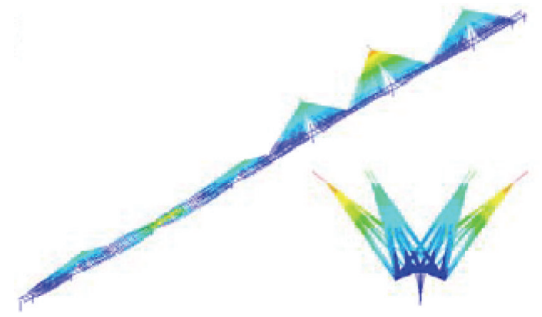

(d) 1st antisymmetric bending of bridge tower in $Z$ direction

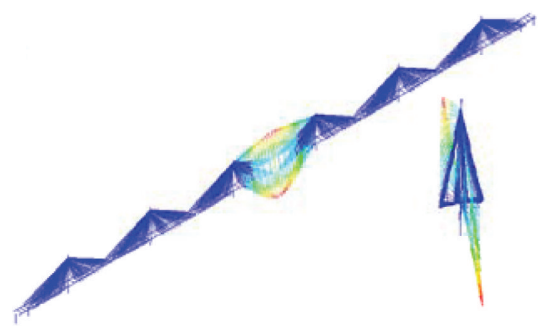

(f) 1st symmetric torsion of bridge deck

Figure 7: Mode shapes of the bridge.

$X$ direction does not occur due to the partially rigid system with longitudinal constraints between the bridge deck and two bridge towers number 2 and number 5, respectively. (ii) The natural frequency of the first symmetric bending of bridge tower in $Z$ direction is found to be $0.2894 \mathrm{~Hz}$ which is the third global vibration mode. Hence, the bridge towers are flexible with small lateral bending stiffness. (iii) The first bending mode of the bridge deck in $Z$ direction with a frequency of $0.7087 \mathrm{~Hz}$ occurs at the 21st global mode, which is higher than the corresponding value $0.2274 \mathrm{~Hz}$ of the first bending mode in $Y$ direction. Thus, the in-plane stiffness of bridge deck is weaker than the out-plane stiffness. (iv) The first torsional mode of the bridge deck with a frequency of $1.1361 \mathrm{~Hz}$ occurs at the $43 \mathrm{rd}$ global mode. Thus, the higher torsional stiffness of the bridge deck is favorable for windresistant performance.

\section{Nonlinear Buffeting Response of the Bridge}

4.1. Simulation of the Wind Field. To perform the nonlinear buffeting analysis of the bridge in the time domain, eight one-dimensional independent multivariable stochastic wind fields are simulated based on the structural configuration as listed in Table 2. One of them is along the bridge deck, one is across the bridge deck, and the other six are across the six bridge towers, respectively. The bridge deck has 95 simulation points, spaced at $30 \mathrm{~m}$ from left to right. And each bridge tower is divided into equal intervals of $10 \mathrm{~m}$ from top to bottom, which results in 16 simulation points.

The longitudinal and vertical nonstationary fluctuating wind speeds in the overall wind field are modeled as 191variate evolutionary vector process, $\mathbf{u}(t)$, and a 95-variate evolutionary vector process, $\mathbf{w}(t)$, respectively. The autospectra adopted for longitudinal and vertical components are Kaimal spectrum and Panofsky spectrum, respectively:

$$
\begin{gathered}
\text { Kaimal spectrum: } \frac{n S_{u}}{u_{*}^{2}}=\frac{200 f}{(1+50 f)^{5 / 3}}, \\
\text { Panof sky spectrum: } \frac{n S_{w}}{u_{*}^{2}}=\frac{6 f}{(1+4 f)^{2}},
\end{gathered}
$$


TABLE 2: Simplified simulation of the wind field.

\begin{tabular}{lcccc}
\hline Number & Location & Component of wind velocity & Spacing & Number of simulation points \\
\hline 1 & Bridge deck & Transverse component $u$ & $30 \mathrm{~m}$ & 95 \\
2 & Bridge deck & Vertical component $w$ & $30 \mathrm{~m}$ & 95 \\
3 & Tower number 1 & Transverse component $u$ & $10 \mathrm{~m}$ & 16 \\
4 & Tower number 2 & Transverse component $u$ & $10 \mathrm{~m}$ & 16 \\
5 & Tower number 3 & Transverse component $u$ & $10 \mathrm{~m}$ & 16 \\
6 & Tower number 4 & Transverse component $u$ & $10 \mathrm{~m}$ & 16 \\
7 & Tower number 5 & Transverse component $u$ & $10 \mathrm{~m}$ & 16 \\
8 & Tower number 6 & Transverse component $u$ & $10 \mathrm{~m}$ & 16 \\
\hline
\end{tabular}

where $S_{u}$ and $S_{w}$ are spectral-density function of longitudinal velocity fluctuation and vertical velocity fluctuation, respectively; $n$ is fluctuation frequency; $f=n z / \bar{U}(z)$ is the Monin coordinate, in which $\bar{U}(z)$ is mean velocity at height $z$ and $\bar{U}(z)=39.3 \times(z / 10)^{0.16}$; and $u_{*}$ is the friction velocity.

The following empirical exponential coherence function is adopted for the velocity cross-spectrum:

$$
\begin{aligned}
& \gamma_{j k}(\omega) \\
& \quad=\exp \left\{-\frac{\omega}{2 \pi} \frac{\left[C_{z}^{2}\left(z_{j}-z_{k}\right)^{2}+C_{x}^{2}\left(x_{j}-x_{k}\right)^{2}\right]^{1 / 2}}{(1 / 2)\left[\bar{U}\left(z_{j}\right)+\bar{U}\left(z_{k}\right)\right]}\right\},
\end{aligned}
$$

where $z_{j}$ and $x_{j}$ are coordinates in the $z$ and $x$ directions, respectively, and $C_{z}$ and $C_{x}$ are 8.3 and 6.4 for longitudinal turbulence components and 3.8 and 4.8 for vertical turbulence components. It should be noted that the coherence between the longitudinal and vertical components is disregarded in the present study.

The longitudinal and vertical fluctuating wind-velocity samples at 95 points on the bridge deck and 96 points on the bridge towers are simulated by using a modified Deodatis method, with a cut-off frequency of $\omega_{u}=5 \pi \mathrm{rad} / \mathrm{s}$, number of fast-Fourier transform $N=1024$, and time interval $\Delta t=0.2 \mathrm{~s}$. Table 3 summarizes the bridge's input condition caused by wind when the wind-induced buffeting is analyzed. Figures 8 and 9 illustrate the autospectra and correlation functions of the longitudinal fluctuating velocities for two points, Point 1 and Point 15 , at the bridge tower number 3 with a distance of $150 \mathrm{~m}$. It should be noted that wind velocities at different points on the bridge seldom reach the maximum value simultaneously. Thus, cross-correlation functions between two different points are important to describe the characteristics of spatial wind field. The correlation value decreases as the distance between the two points increases. As can be seen from the figure, the simulated autospectra and correlation functions are in well agreement with the targets.

\subsection{Wind-Induced Buffeting Response of the Bridge}

4.2.1. Buffeting Analysis Method. The simulated fluctuating wind speed time histories are used as inputs to obtain the buffeting responses of the Jiashao Bridge in the time domain. The buffeting analysis is carried out in the software package ANSYS with the following steps [12, 15]: (1) A 3D finite
TABLE 3: Parameters for the bridge's input condition caused by wind.

\begin{tabular}{lc}
\hline Parameter & Value \\
\hline Average height of bridge deck & $43.48 \mathrm{~m}$ \\
Spacing of simulation points of bridge deck & $30 \mathrm{~m}$ \\
Spacing of simulation points of bridge towers & $10 \mathrm{~m}$ \\
Ground roughness & 0.01 \\
Mean velocity at height of $10 \mathrm{~m}$ & $39.3 \mathrm{~m} / \mathrm{s}$ \\
Design wind velocity at the bridge deck & $49.72 \mathrm{~m} / \mathrm{s}$ \\
Cut-off frequency & $\omega_{n}=5 \pi$ \\
Number of fast-Fourier transform & $N=1024$ \\
Time interval & $\Delta t=0.2 \mathrm{~s}$ \\
Simulated sampling points & $N T=3000$ \\
Time length of simulated sampling & $T=600 \mathrm{~s}$ \\
\hline
\end{tabular}

element model of the bridge is established using the software package ANSYS. (2) In order to account for self-excited aerodynamic forces, element aeroelastic stiffness and aeroelastic damping are both incorporated in buffeting analysis through the user-defined Matrix27 element in ANSYS $[5,10,12]$. (3) The steady aerodynamic forces and buffeting forces are calculated by the measured aerodynamic coefficients and the Devaport formula, respectively [16]. (4) The self-excited aerodynamic forces, buffeting forces, and steady aerodynamic forces are applied as external loadings to the structural model to analyze the buffeting responses of the bridge in time domain $[5,12]$. It should be noted that the effect of the aerodynamic admittance is disregarded because it was not available from wind-tunnel tests. And the aerodynamic force coefficients and flutter derivatives are measured through the wind-tunnel tests.

4.2.2. Buffeting Responses of the Bridge Deck. The buffeting responses of the Jiashao Bridge were calculated at the design wind velocity of $49.72 \mathrm{~m} / \mathrm{s}$ at the bridge deck for the return period of 100 years. Figure 10 shows the time histories of vertical, horizontal, and torsional buffeting displacements of the 33rd simulation point at the bridge deck, which is located in the middle of the girder span between bridge towers number 2 and number 3. The root-mean-square (RMS) buffeting displacements of all simulation points at the bridge deck are further calculated as shown in Figure 11. It can be seen from the figure that the vertical and torsional buffeting displacements are approximately symmetrically distributed along the bridge deck. However, there is no symmetry in the distribution of the horizontal buffeting displacements. 


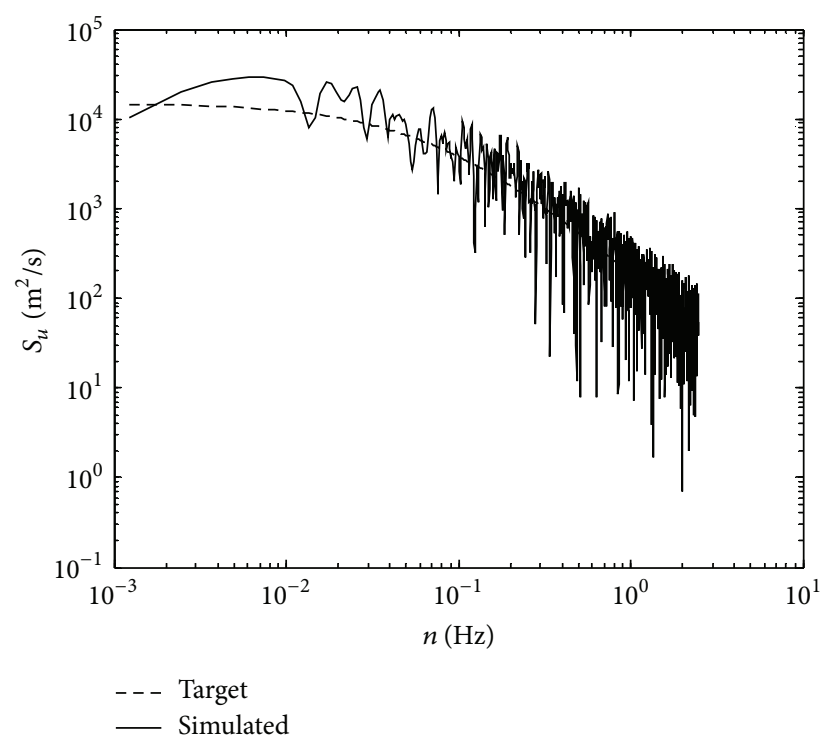

(a) Autospectrum of Point 1

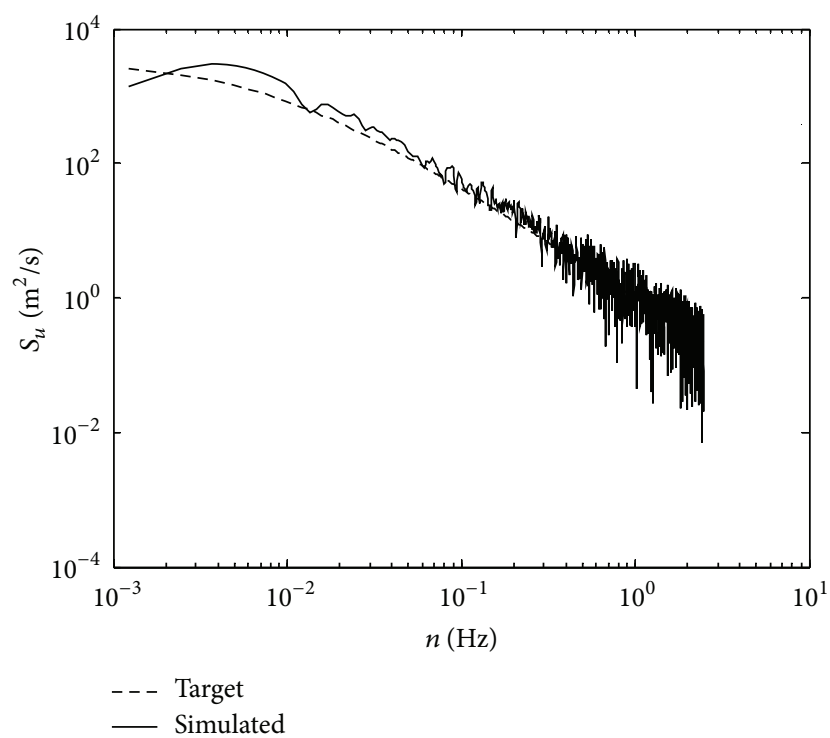

(b) Autospectrum of Point 15

FIGURE 8: Autospectra of longitudinal fluctuating wind velocities at bridge tower number 3.

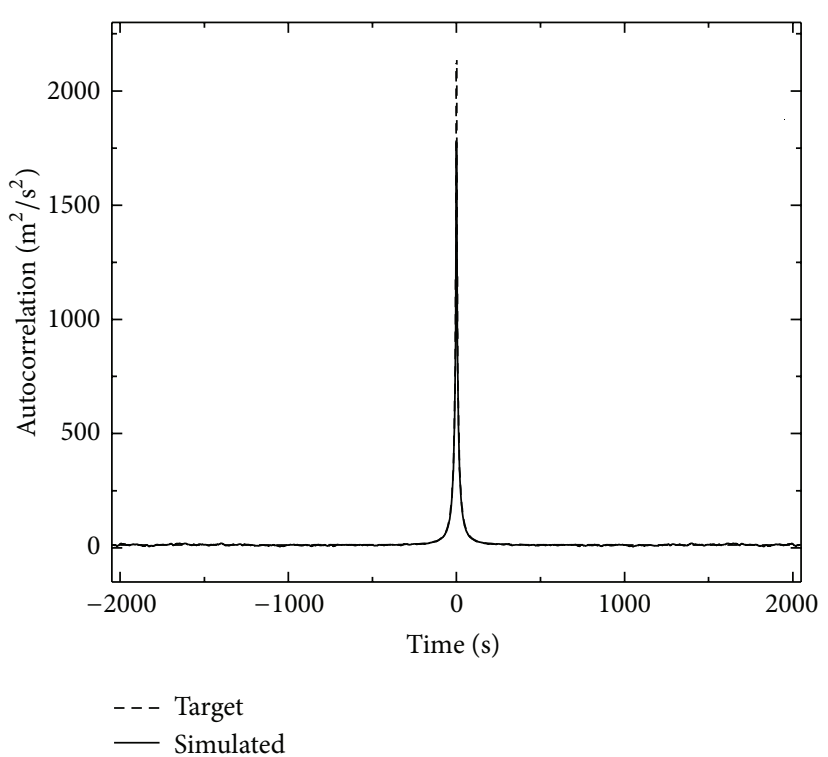

(a) Autocorrelation of Point 1

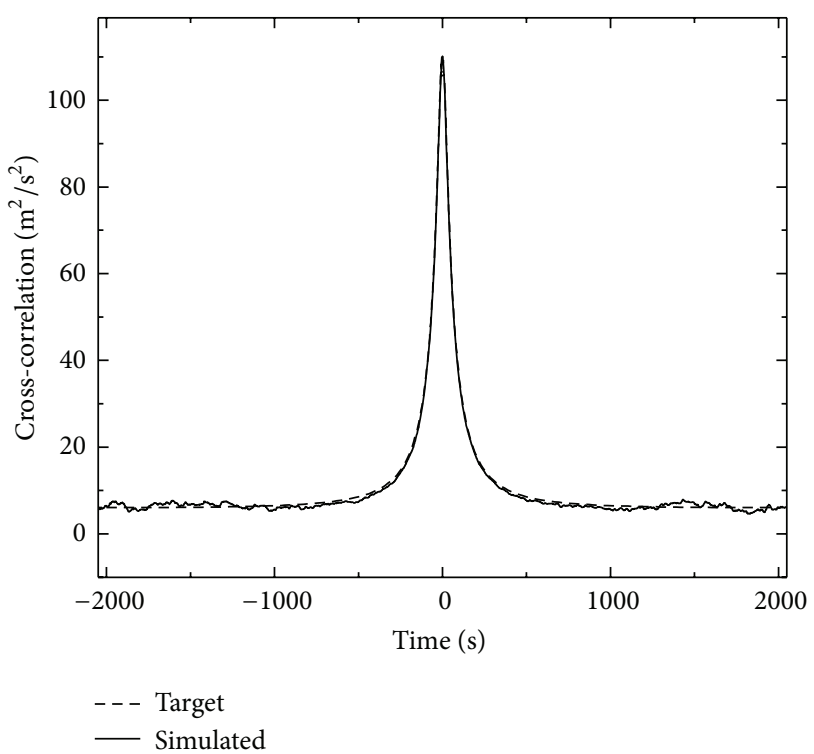

(b) Cross-correlation between Points 1 and 15

FIGURE 9: Correlation functions of longitudinal fluctuating wind velocities at bridge tower number 3.

Moreover, the horizontal buffeting displacements at the girder midspan are significantly larger than those of other girder spans due to the installation of the rigid hinge in the middle of the midspan of the bridge deck, which will be discussed in the subsequent Section 5.2.

In order to investigate the contribution of the responses at different frequencies to the overall buffeting response, the power spectra of vertical, horizontal, and torsional buffeting displacements are calculated and Figure 12 shows the displacement spectra at the girder midspan. The following can be seen:

(i) In the spectrum of vertical buffeting displacement, the first and second peaks correspond to the first and second symmetric bending modes of the bridge deck in $Y$ direction, respectively. Thus, the vertical buffeting displacement at the girder midspan mainly depends on the symmetric bending mode of the bridge deck in $Y$ direction.

(ii) In the spectrum of horizontal buffeting displacement, the first and second peaks correspond to the 2nd symmetric bending of bridge tower in $Z$ direction and the 1st symmetric bending of bridge deck in $Z$ direction, respectively. Thus, the horizontal buffeting displacement at the girder midspan mainly depends on the coupling effect of the symmetric bending modes of bridge tower and bridge deck in $Z$ direction. 


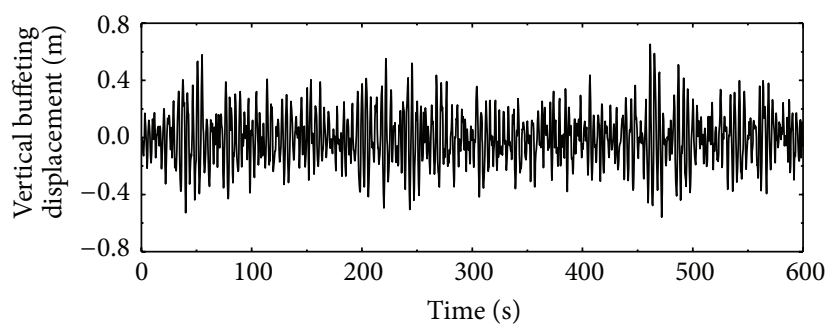

(a) Time histories of vertical buffeting displacement

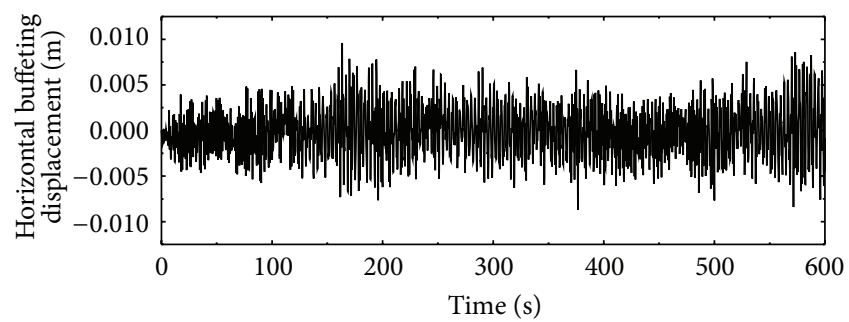

(b) Time histories of horizontal buffeting displacement

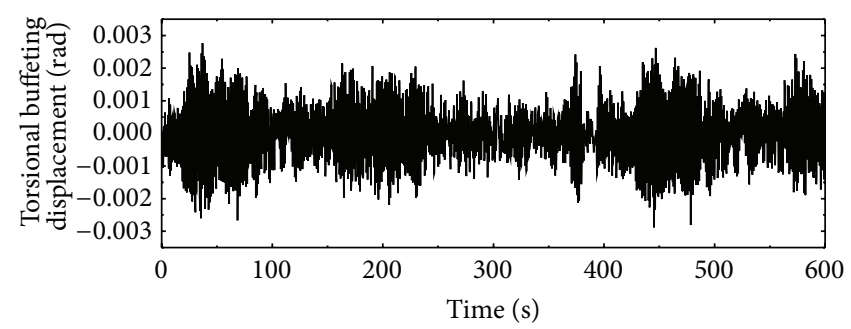

(c) Time histories of torsional buffeting displacement

FIGURE 10: Time histories of buffeting displacements of the 33rd simulation point at the bridge deck.

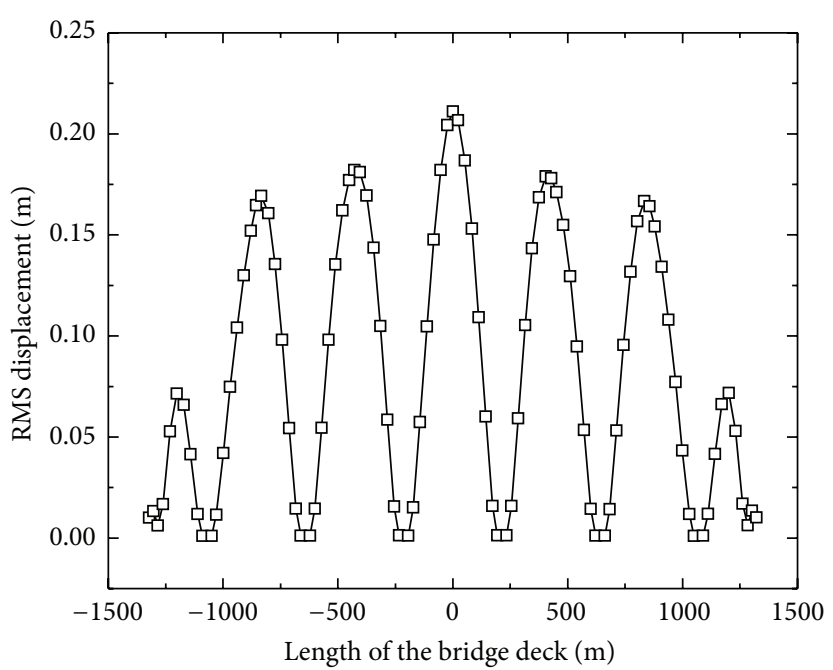

(a) RMS vertical buffeting displacements

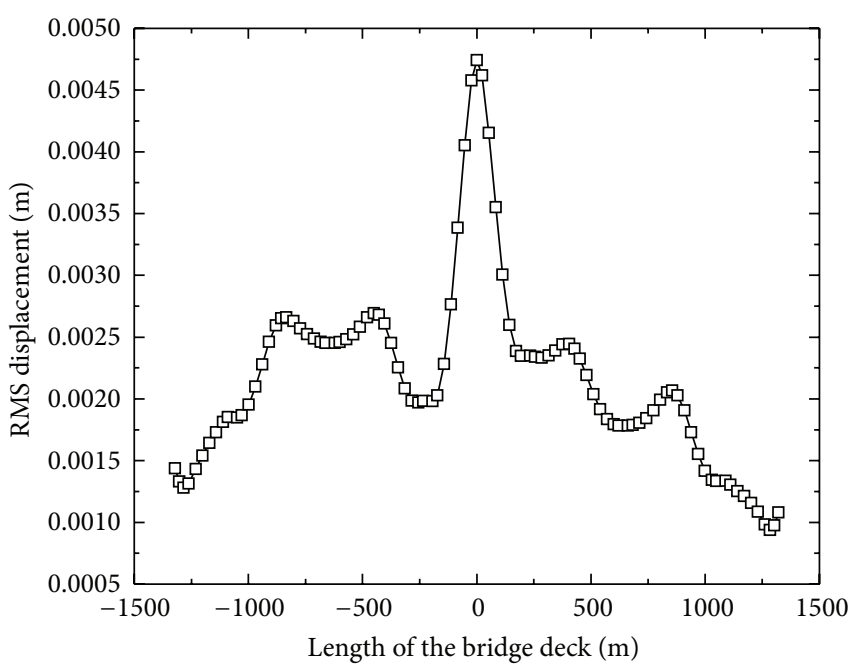

(b) RMS horizontal buffeting displacements

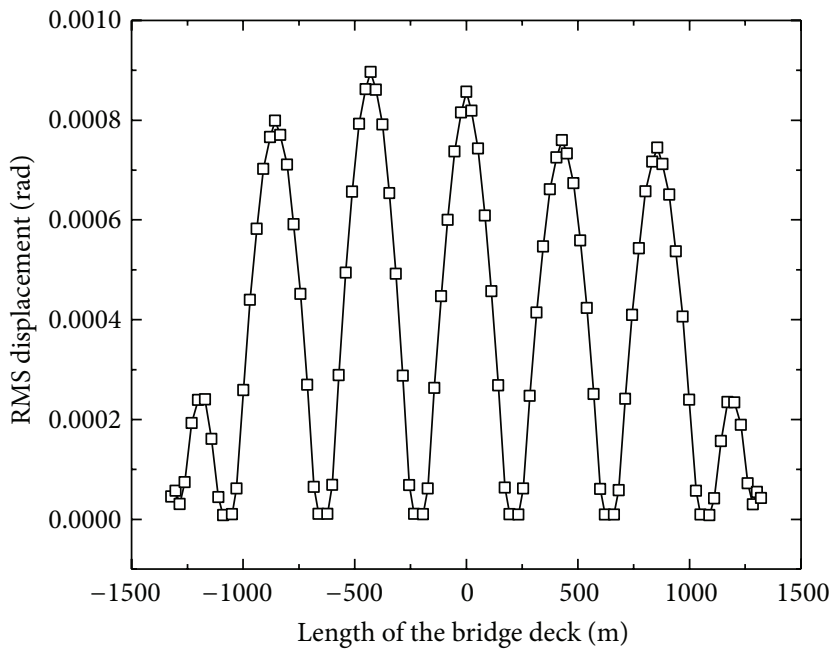

(c) RMS torsional buffeting displacements

FIGURE 11: RMS buffeting displacements of the bridge deck. 


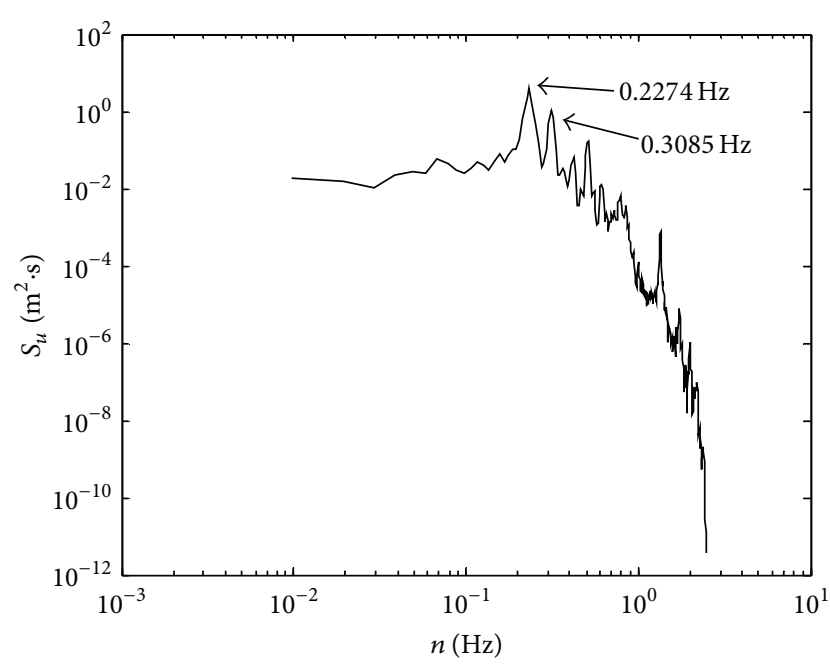

(a) Power spectrum of vertical buffeting displacement

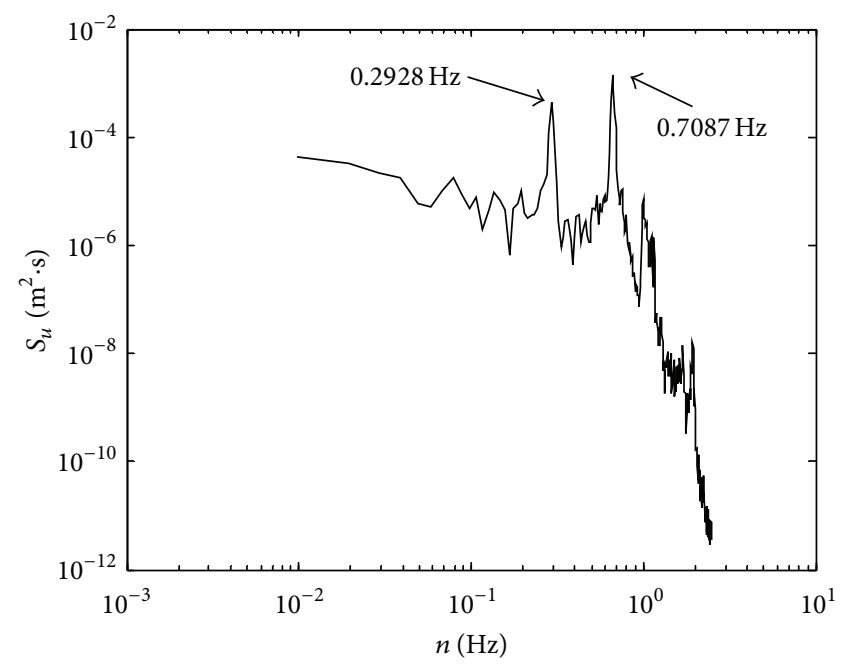

(b) Power spectrum of horizontal buffeting displacement

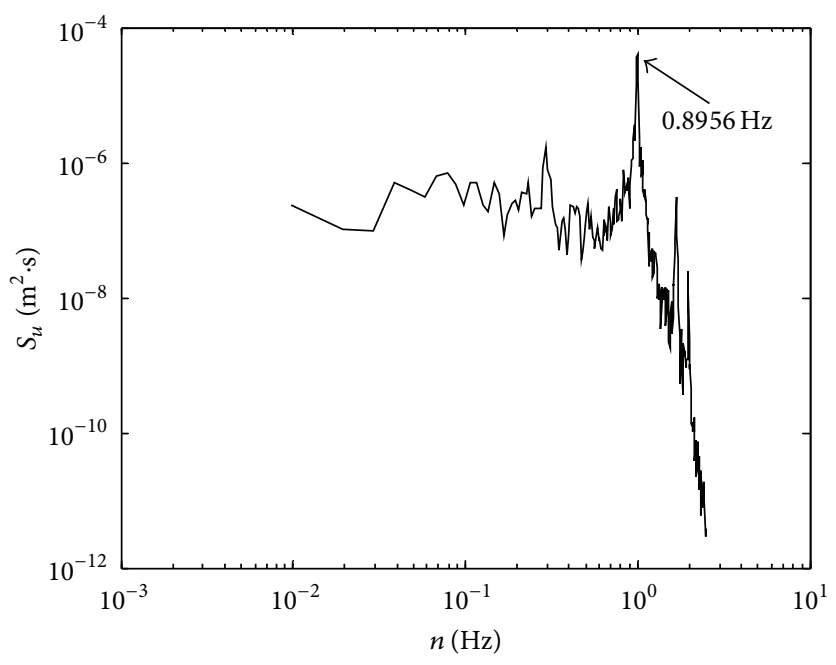

(c) Power spectrum of torsional buffeting displacement

FIGURE 12: Power spectra of buffeting displacements in the middle of the bridge deck.

(iii) In the spectrum of torsional buffeting displacement, the first peak corresponds to the couple mode of the antisymmetric bending of bridge deck in $Z$ direction and antisymmetric bending of bridge tower in $Z$ direction, which indicates that the torsional buffeting displacement at the girder midspan mainly depends on the coupling effect of antisymmetric bending mode of bridge tower and bridge deck in $Z$ direction.

4.2.3. Buffeting Responses of the Bridge Towers. The RMS buffeting responses of all simulation points at each bridge tower are calculated in the longitudinal and transverse directions, respectively. Figures 13(a) and 13(b) show the longitudinal RMS buffeting displacements and bending moments along the bridge towers, respectively. It can be seen that the longitudinal buffeting responses of bridge towers are approximately symmetrically distributed. And the longitudinal buffeting responses of the side towers (towers number 1 and number
6) are significantly smaller than those of other towers. This is because side towers are connected through outermost stay cables to the anchor piers, which can provide effective support to the side towers [2]. However, the beneficial effect of the anchor piers diminishes for the central towers and hence the longitudinal stiffness of the central towers is smaller than that of the side towers. In addition, the base bending moments of the towers number 2 and number 5 are significantly larger than those of towers number 3 and number 4 due to the partially longitudinal constraints at bridge towers number 2 and number 5. Thus, part of bridge towers longitudinally restricted with the bridge deck results in the concentration effect of longitudinal base moments. Figure 13(c) further shows the power spectrum of longitudinal buffeting displacement on the top of bridge tower number 3 . It can be seen that the first, second, and third peaks correspond to the 1st, 9th, and 10th modes, which are all coupling modes of bending of the bridge deck in $Y$ direction and bending of bridge tower in $X$ direction. 


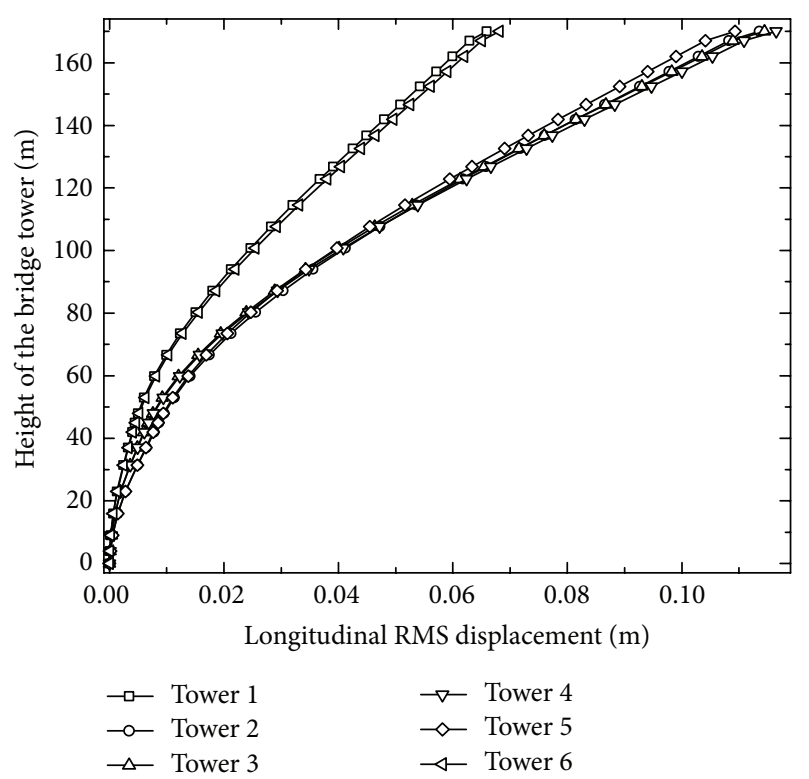

(a) Longitudinal RMS buffeting displacements

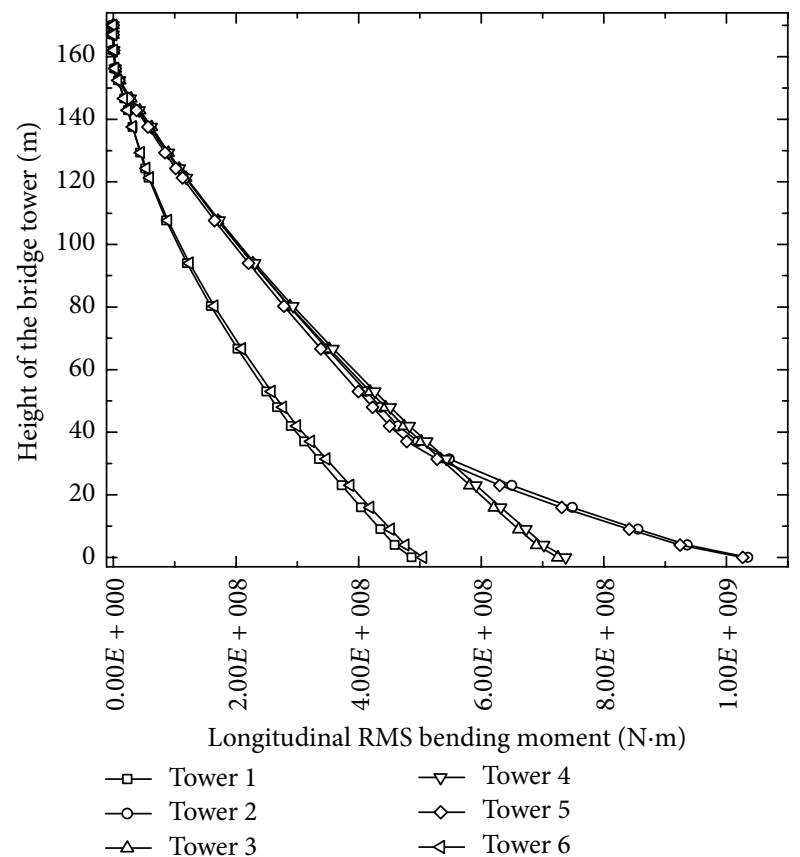

(b) Longitudinal RMS buffeting bending moments

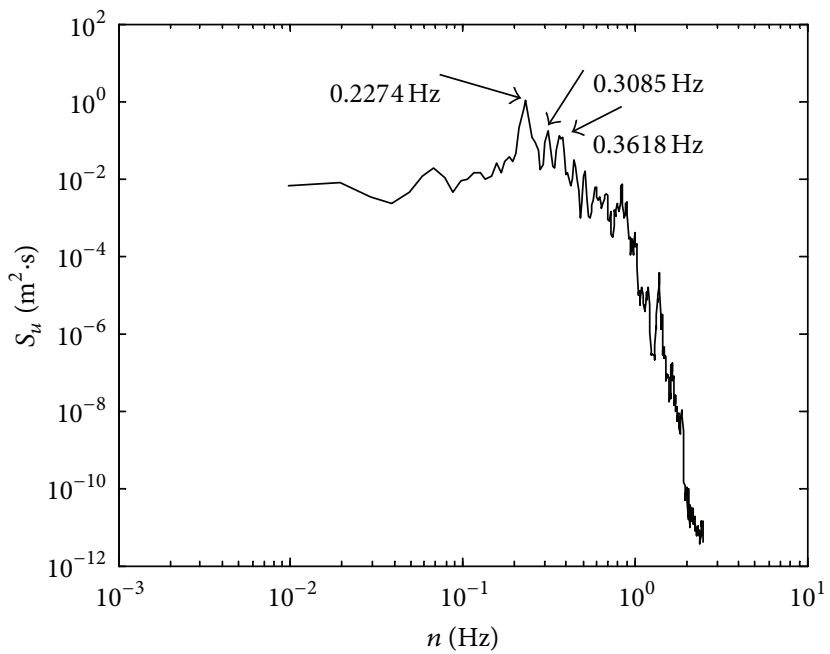

(c) Power spectrum of longitudinal buffeting displacement on the top of bridge tower number 3

FIGURE 13: Longitudinal buffeting responses of bridge towers.

Figures 14(a) and 14(b) show the transverse RMS buffeting displacements and bending moments along the bridge towers, respectively. There is no symmetry in the distribution of the transverse buffeting responses of bridge towers. The transverse buffeting responses of towers number 2 and number 4 are maximum and the transverse buffeting response of tower number 6 is minimum. And there is no concentration effect of transverse base moments due to partially longitudinal constraints. Therefore, the effect of partially longitudinal constraints should be taken into account especially for analyzing the buffeting base moments of the bridge towers longitudinally restricted with the bridge deck. Figure 14(c) further shows the power spectrum of transverse buffeting displacement on the top of bridge tower number 3. It can be seen that the first peak corresponds to the 5th mode, namely, the 2nd symmetric bending of bridge tower in $Z$ direction.

\section{Discussions}

5.1. Influence of Self-Excited Forces on the Buffeting Response. The self-excited aerodynamic forces are induced by interaction between bridge and wind motions. In this section, the influence of self-excited forces on the buffeting responses of Jiashao Bridge is discussed. Figure 15 shows the RMS of displacement responses at the bridge deck with and 


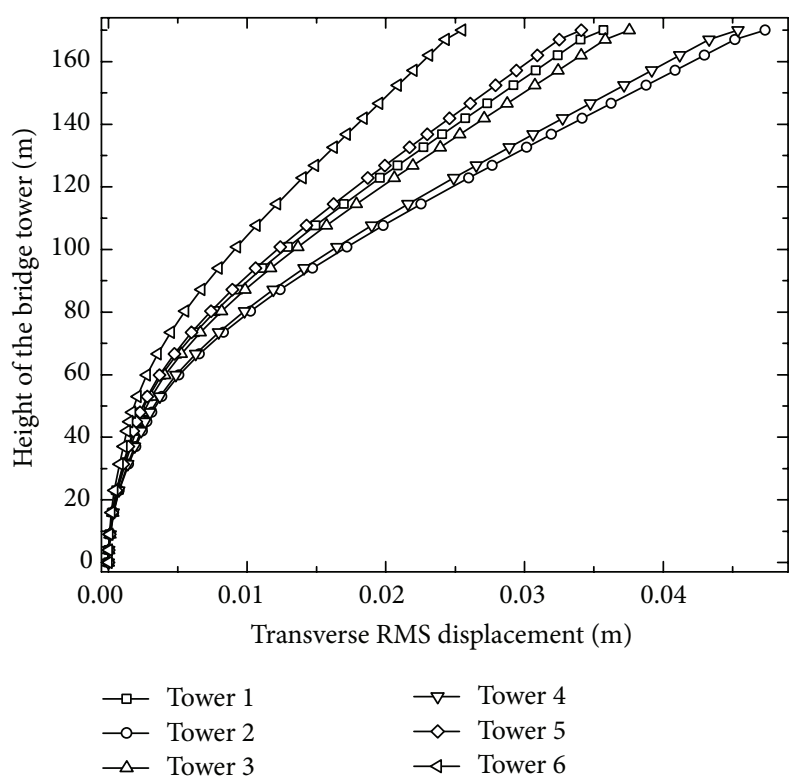

(a) Transverse RMS buffeting displacements

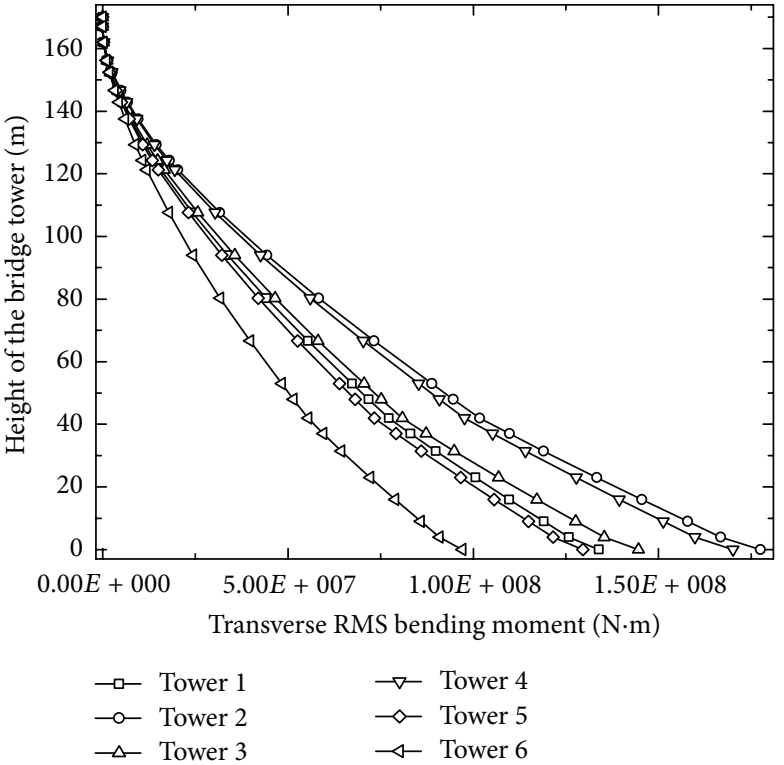

(b) Transverse RMS buffeting bending moments

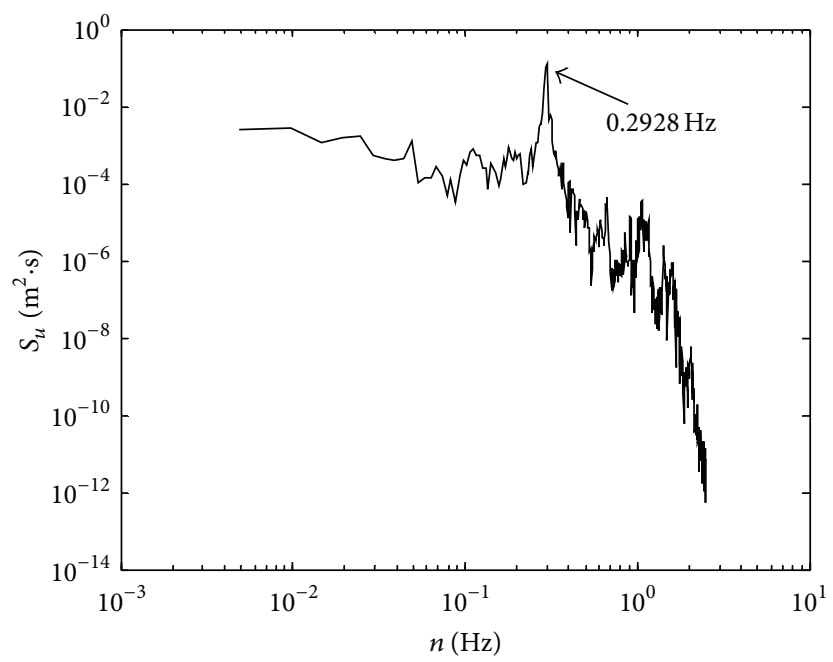

(c) Power spectrum of transverse buffeting displacement on the top of bridge tower number 3

FIGURE 14: Transverse buffeting responses of bridge towers.

without considering self-excited forces. It can be shown in Figure 15(a) that the vertical buffeting displacements obtained with considering self-excited forces are significantly smaller than those obtained without considering self-excited forces. The RMS vertical displacement at the girder midspan obtained with considering self-excited forces is 2.57 times as that obtained without considering self-excited forces. However, Figures 15(b) and 15(c) show that the horizontal and torsional buffeting displacements obtained with considering self-excited forces are a little smaller than those obtained without considering self-excited forces.

Generally, the self-excited forces acting on the bridge towers can be disregarded. However, it is necessary to investigate the effect of self-excited force acting on the bridge deck on the buffeting responses of bridge towers. Figure 16 shows the RMS of displacements and bending moments of bridge tower number 3 with and without considering selfexcited forces. It can be seen that the self-excited forces acting on the bridge deck have little effect on the transverse buffeting displacements and bending moments of the bridge tower. However, the longitudinal buffeting displacements and bending moments of the bridge tower are significantly reduced due to the self-excited force effect. The reason is that the mitigating effect on the vertical buffeting displacements of the bridge deck can also reduce the longitudinal buffeting responses of the bridge towers due to the dynamic coupling between the bending of bridge towers in $X$ direction and bending of the bridge deck in $Y$ direction. Therefore, the selfexcited force effect should be taken into account especially for analyzing the vertical buffeting responses of the bridge deck and longitudinal buffeting responses of the bridge towers. 


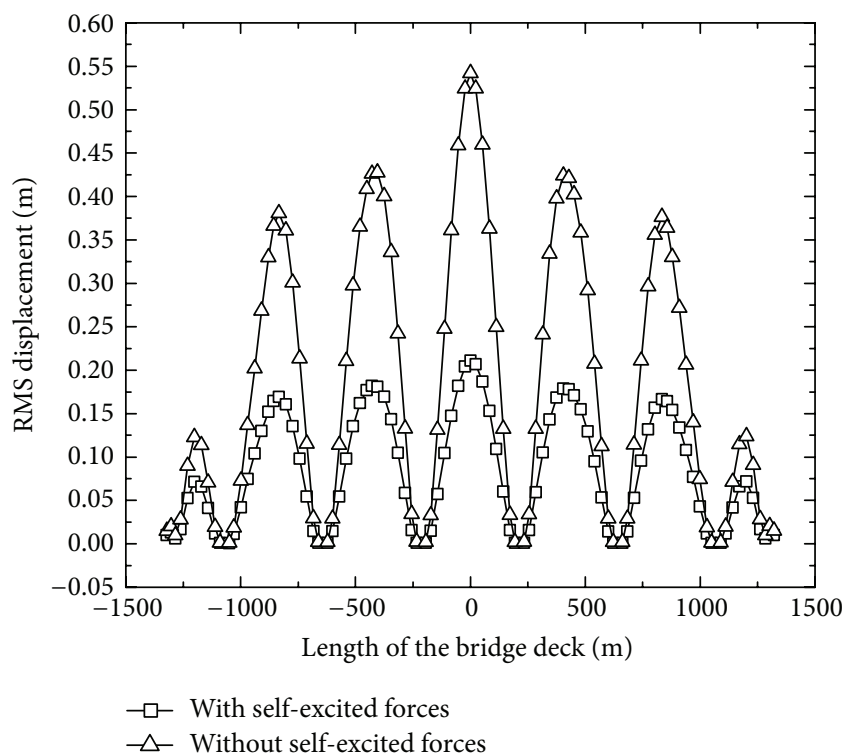

(a) RMS vertical buffeting displacements

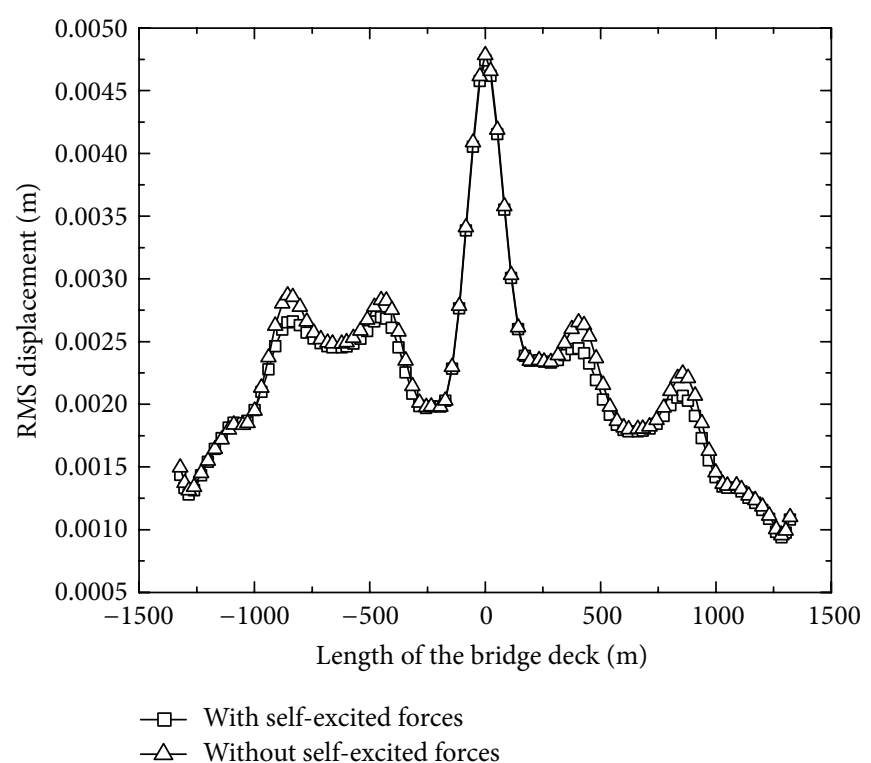

(b) RMS horizontal buffeting displacements

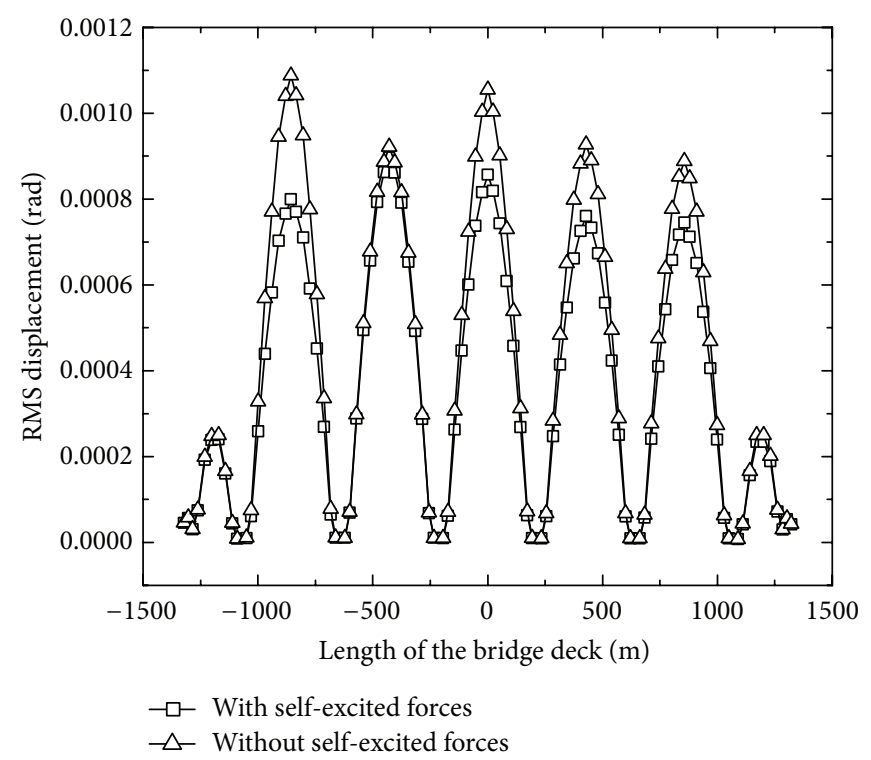

(c) RMS torsional buffeting displacements

FIGURE 15: Comparisons of RMS buffeting responses of bridge deck.

5.2. Influence of Rigid Hinge on the Buffeting Response. The rigid hinge installed in the middle of the bridge deck is very important to release the temperature-induced deformation in the bridge deck. In this section, the effect of rigid hinge on the buffeting responses of the bridge is investigated. The contrast analytical model without rigid hinge is developed and the modal analysis result of the contrast model is shown in Table 4. It can be seen that the modal frequency of the first symmetric bending mode of bridge deck in $Z$ direction of the contrast model without rigid hinge is $0.8610 \mathrm{~Hz}$, while the modal frequency of the original model with rigid hinge is $0.7087 \mathrm{~Hz}$. The relative variation is about $21.50 \%$. And the rigid hinge has a limited effect on the other global vibration modes.
The buffeting response analysis of the contrast model without rigid hinge is carried out. The comparisons between the buffeting responses obtained with and without rigid hinge indicate that the installation of rigid hinge has little effect on the vertical and torsional buffeting responses of the bridge deck and buffeting responses of bridge towers. However, the installation of rigid hinge has a significant effect on the horizontal buffeting displacements of the bridge deck as shown in Figure 17(a). It can be seen that the horizontal buffeting displacement in the girder midspan obtained with rigid hinge is approximately 2 times as that obtained without the rigid hinge. Figure 17(b) shows the spectra of horizontal buffeting displacements obtained with and without rigid hinge. It can be shown that the frequency of the second peak 


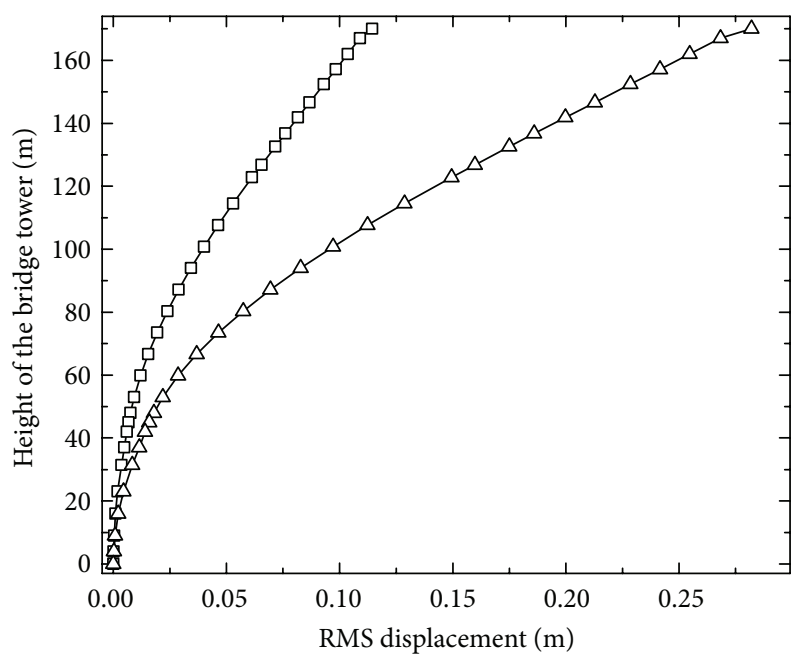

$\rightarrow-$ With self-excited forces

$\triangle-$ Without self-excited forces

(a) Longitudinal RMS buffeting displacements

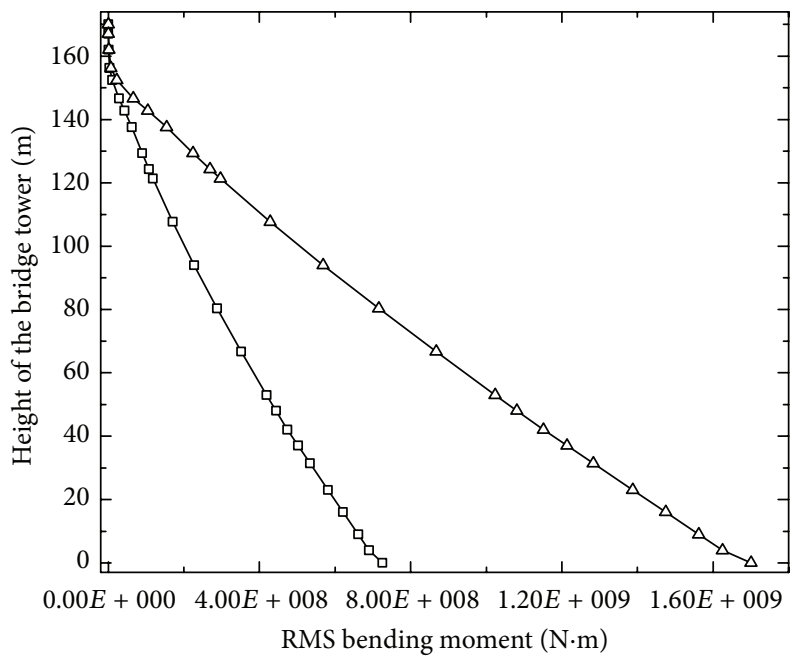

$\neg-$ With self-excited forces

$-\triangle$ Without self-excited forces

(c) Longitudinal RMS buffeting bending moments

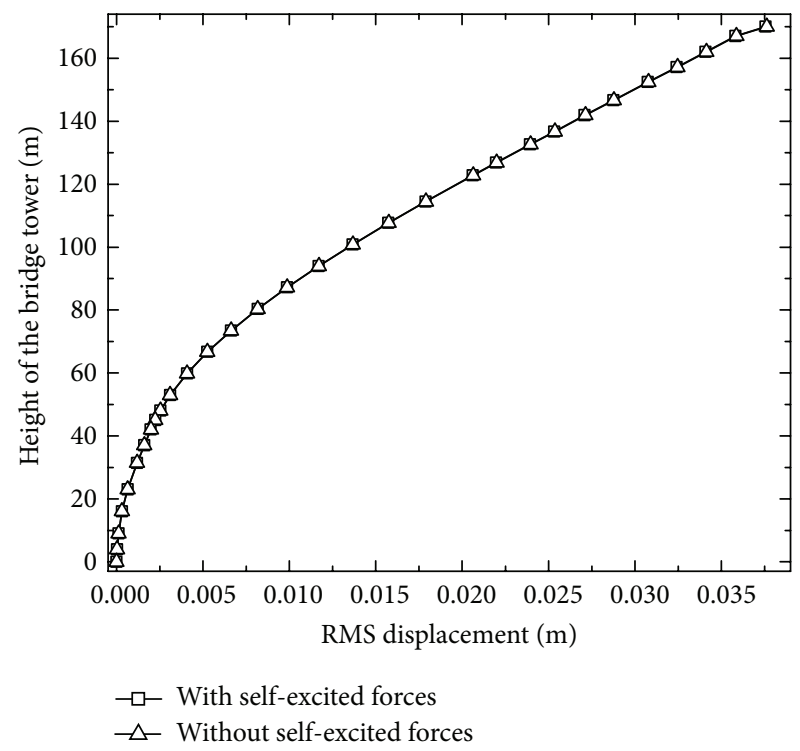

(b) Transverse RMS buffeting displacements

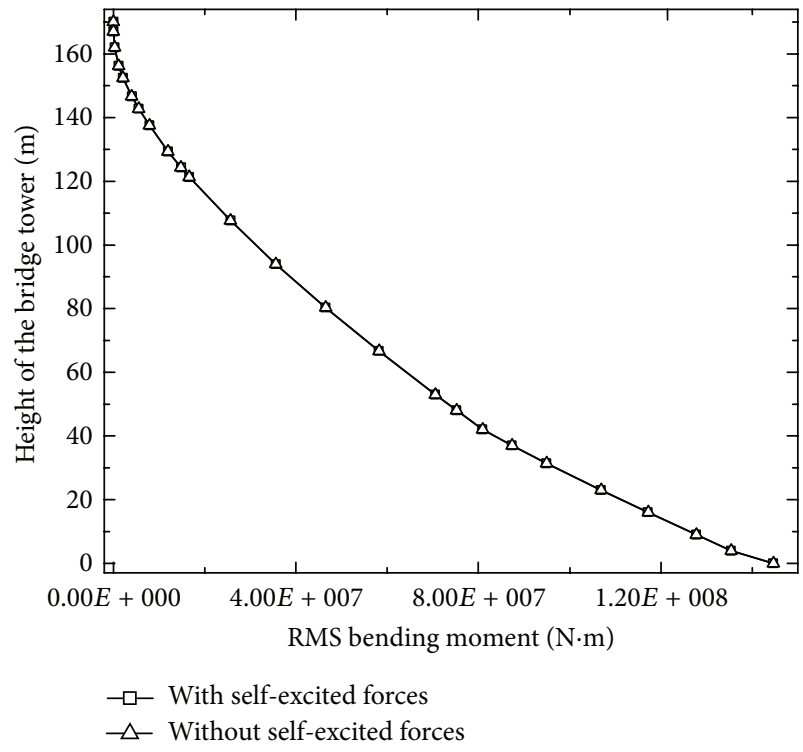

(d) Transverse RMS buffeting bending moments

FIGURE 16: Comparisons of RMS buffeting responses of bridge tower number 3.

corresponding to the 1st symmetric bending of bridge deck in $Z$ direction increases from $0.7087 \mathrm{~Hz}$ with rigid hinge to $0.8610 \mathrm{~Hz}$ without rigid hinge. Moreover, the spectrum amplitude of the second peak obtained without rigid hinge is smaller than that obtained with rigid hinge. Therefore, the effect of the installation of the rigid hinge in the middle of the bridge deck should be taken into account for analyzing the horizontal buffeting responses of the bridge deck.

\section{Conclusions}

The Jiashao Bridge in China is a six-tower cable-stayed bridge, which is the longest multispan cable-stayed bridge in the world. In this paper, the nonlinear buffeting responses of the bridge were obtained using a time-domain procedure for analyzing buffeting responses implemented in ANSYS, focusing on the characteristics of buffeting responses of the bridge. From the analytical results of the present study the following conclusions are drawn:

(1) The vertical and torsional buffeting displacements along the bridge deck are approximately symmetrically distributed. However, there is no symmetry in the distribution of the horizontal buffeting displacements. The power spectrum analysis results indicate that, for the girder midspan, the vertical buffeting displacement is dominated by the symmetric bending mode of the bridge deck in $Y$ direction; the horizontal buffeting displacement is dominated by the coupling 
TABLE 4: Influence of rigid hinge on the dynamic characteristics of the bridge.

\begin{tabular}{|c|c|c|c|}
\hline \multicolumn{2}{|c|}{ Modal frequency/Hz } & \multirow{2}{*}{ Relative variation (\%) } & \multirow{2}{*}{ Description of vibration modes } \\
\hline Original model & Contrast model & & \\
\hline 0.2274 & 0.2299 & 1.10 & $\begin{array}{l}\text { 1st symmetric bending of bridge deck in } Y \text { direction }+ \text { symmetric bending } \\
\text { of bridge tower in } X \text { direction }\end{array}$ \\
\hline 0.2615 & 0.2615 & 0.00 & $\begin{array}{l}\text { 1st antisymmetric bending of bridge deck in } Y \text { direction }+ \text { antisymmetric } \\
\text { bending of bridge tower in } X \text { direction }\end{array}$ \\
\hline 0.2894 & 0.2894 & 0.00 & 1st symmetric bending of bridge tower in $Z$ direction \\
\hline 0.2907 & 0.2907 & 0.00 & 1st antisymmetric bending of bridge tower in $Z$ direction \\
\hline 0.2928 & 0.2928 & 0.00 & 2nd symmetric bending of bridge tower in $Z$ direction \\
\hline 0.2950 & 0.2950 & 0.00 & 2 nd antisymmetric bending of bridge tower in $Z$ direction \\
\hline 0.2965 & 0.2965 & 0.00 & 3rd symmetric bending of bridge tower in $Z$ direction \\
\hline 0.2970 & 0.2970 & 0.00 & 3rd antisymmetric bending of bridge tower in $Z$ direction \\
\hline 0.3085 & 0.3089 & 0.13 & $\begin{array}{l}\text { 2nd symmetric bending of bridge deck in } Y \text { direction }+ \text { symmetric bending } \\
\text { of bridge tower in } X \text { direction }\end{array}$ \\
\hline 0.3618 & 0.3618 & 0.00 & $\begin{array}{l}\text { 2nd antisymmetric bending of bridge deck in } Y \text { direction }+ \text { antisymmetric } \\
\text { bending of bridge tower in } X \text { direction }\end{array}$ \\
\hline 0.6779 & 0.6779 & 0.00 & Bending of bridge piers in $X$ direction \\
\hline 0.7087 & 0.8610 & 21.49 & $\begin{array}{l}\text { 1st symmetric lateral bending of bridge deck in } Z \text { direction }+ \text { symmetric } \\
\text { lateral bending of bridge tower in } Z \text { direction }\end{array}$ \\
\hline 0.8956 & 0.8956 & 0.00 & $\begin{array}{l}\text { 1st antisymmetric bending of bridge deck in } Z \text { direction }+ \text { antisymmetric } \\
\text { bending of bridge tower in } Z \text { direction }\end{array}$ \\
\hline 1.1361 & 1.1386 & 0.22 & 1st symmetric torsion of bridge deck \\
\hline 1.1389 & 1.1389 & 0.00 & 2nd symmetric torsion of bridge deck \\
\hline 1.1391 & 1.1392 & 0.01 & 3rd symmetric torsion of bridge deck \\
\hline
\end{tabular}

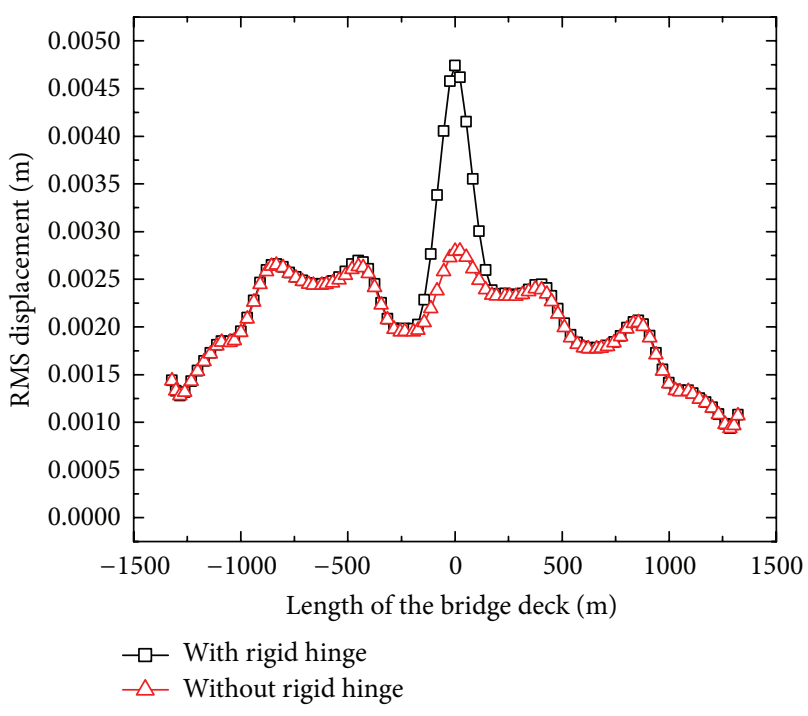

(a) RMS horizontal buffeting displacements

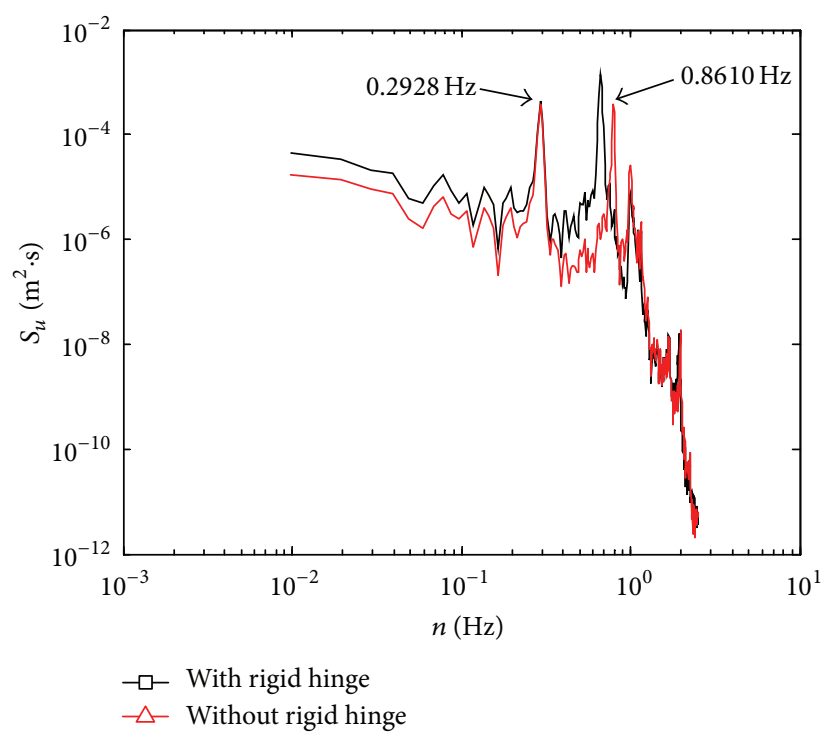

(b) Power spectrum of horizontal buffeting displacement

FIGURE 17: Influence of rigid hinge on the horizontal buffeting displacements of bridge deck.

effect of the symmetric bending modes of bridge tower and bridge deck in $Z$ direction; the torsional buffeting displacement is dominated by the coupling effect of antisymmetric bending mode of bridge tower and bridge deck in $Z$ direction.

(2) The longitudinal buffeting responses of bridge towers are approximately symmetrically distributed. And there is no symmetry in the distribution of the transverse buffeting responses of bridge towers. The power spectrum analysis results indicate that the longitudinal buffeting displacement is dominated by the coupling effect of bending of the bridge deck in $Y$ direction and bending of bridge tower in $X$ direction; the transverse buffeting displacement is dominated by the bending of bridge tower in $Z$ direction.

(3) Due to the small longitudinal stiffness of the central towers, the longitudinal buffeting responses of the central towers are significantly larger than those of 
side towers in the multispan cable-stayed bridge. And part of bridge towers longitudinally restricted with the bridge deck results in the concentration effect of longitudinal base moments. The base moments of bridge towers longitudinally restricted with the bridge deck are significantly larger than those of bridge towers longitudinally unrestricted with the bridge deck.

(4) The self-excited force effect has a significant mitigating effect on reducing the vertical buffeting displacements of the bridge deck and longitudinal buffeting responses of the bridge towers due to the dynamic coupling between the bending of bridge towers in $X$ direction and bending of the bridge deck in $Y$ direction. And the self-excited force effect has a little effect on the horizontal and torsional buffeting displacements of the bridge deck and transverse buffeting responses of the bridge towers.

(5) The installation of rigid hinge in the middle of the bridge deck has little effect on the vertical and torsional buffeting responses of the bridge deck and buffeting responses of bridge towers. However, the horizontal buffeting displacement in the girder midspan obtained with rigid hinge is approximately 2 times as that obtained without the rigid hinge. The reason is that the installation of rigid hinge reasonably reduces the modal frequency of the first symmetric bending mode of bridge deck in $Z$ direction and increases the corresponding spectrum amplitude, which deserves special attention in practice.

\section{Conflict of Interests}

The authors declare that there is no conflict of interests regarding the publication of this paper.

\section{Acknowledgments}

The authors gratefully acknowledge the National Basic Research Program of China (973 Program) (no. 2015CB060000), the National Science and Technology Support Program of China (no. 2014BAG07B01), the National Natural Science Foundation of China (no. 51438002 and no. 51278106), the Program of "Six Major Talent Summit" Foundation (no. 1105000268), and Key Program of Ministry of Transport (no. 2013319223120).

\section{References}

[1] M. Virlogeux, "Recent evolution of cable-stayed bridges," Engineering Structures, vol. 21, no. 8, pp. 737-755, 1999.

[2] Y. Q. Ni, J. Y. Wang, and L. C. Lo, "Influence of stabilizing cables on seismic response of a multispan cable-stayed bridge," Computer-Aided Civil and Infrastructure Engineering, vol. 20, no. 2, pp. 142-153, 2005.

[3] C. Barre, O. Flamand, and G. Grillaud, "The Millau viaductspecial wind studies for an exceptional structure," in Proceedings of the 10th International Conference on Wind Engineering, Copenhagen, Denmark, 1999.

[4] P. Papanikolas, "The Rion-Antirion multispan cable-stayed bridge," in Proceedings of the 2nd MIT Conference on Computational Fluid and Solid Mechanics, Cambridge, UK, 2003.

[5] Z. Q. Chen, Y. Han, X. G. Hua, and Y. Z. Luo, "Investigation on influence factors of buffeting response of bridges and its aeroelastic model verification for Xiaoguan Bridge," Engineering Structures, vol. 31, no. 2, pp. 417-431, 2009.

[6] Y.-L. Xu, L. Hu, and A. Kareem, "Conditional simulation of nonstationary fluctuating wind speeds for long-span bridges," Journal of Engineering Mechanics, vol. 140, no. 1, pp. 61-73, 2014.

[7] H. Katsuchi, N. P. Jones, and R. H. Scanlan, "Multimode coupled flutter and buffeting analysis of the Akashi-Kaikyo bridge," Journal of Structural Engineering, vol. 125, no. 1, pp. 60-69, 1999.

[8] X. Chen, M. Matsumoto, and A. Kareem, "Time domain flutter and buffeting response analysis of bridges," Journal of Engineering Mechanics, vol. 126, no. 1, pp. 7-16, 2000.

[9] A. G. Chowdhury and P. P. Sarkar, "Experimental identification of rational function coefficients for time-domain flutter analysis," Engineering Structures, vol. 27, no. 9, pp. 1349-1364, 2005.

[10] X. G. Hua and Z. Q. Chen, "Full-order and multimode flutter analysis using ANSYS," Finite Elements in Analysis and Design, vol. 44, no. 9-10, pp. 537-551, 2008.

[11] W. W. Guo, Y. L. Xu, H. Xia, W. S. Zhang, and K. M. Shum, "Dynamic response of suspension bridge to typhoon and trains. II: numerical results," Journal of Structural Engineering, vol. 133, no. 1, pp. 12-21, 2007.

[12] H. Wang, A. Q. Li, and R. M. Hu, "Comparison of ambient vibration response of the Runyang Suspension Bridge under skew winds with time-Domain numerical predictions," Journal of Bridge Engineering, vol. 16, no. 4, pp. 513-526, 2011.

[13] C. Su, X. Fan, and T. He, "Wind-induced vibration analysis of a cable-stayed bridge during erection by a modified time-domain method," Journal of Sound and Vibration, vol. 303, no. 1-2, pp. 330-342, 2007.

[14] H. J. Ernst, "The E-molule of rope with consideration of the dip," The Civil Engineering, vol. 40, no. 1, pp. 52-55, 1965.

[15] H. Wang, R. M. Hu, J. Xie, T. Tong, and A. Q. Li, "Comparative study on buffeting performance of sutong bridge based on design and measured spectrum," Journal of Bridge Engineering, vol. 18, no. 7, pp. 587-600, 2013.

[16] A. R. Chen, X. F. He, and H. F. Xiang, "Identification of 18 flutter derivatives of bridge decks," Journal of Wind Engineering and Industrial Aerodynamics, vol. 90, no. 12-15, pp. 2007-2022, 2002. 


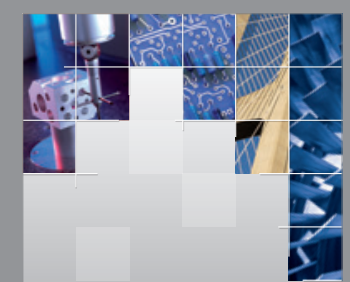

\section{Enfincering}
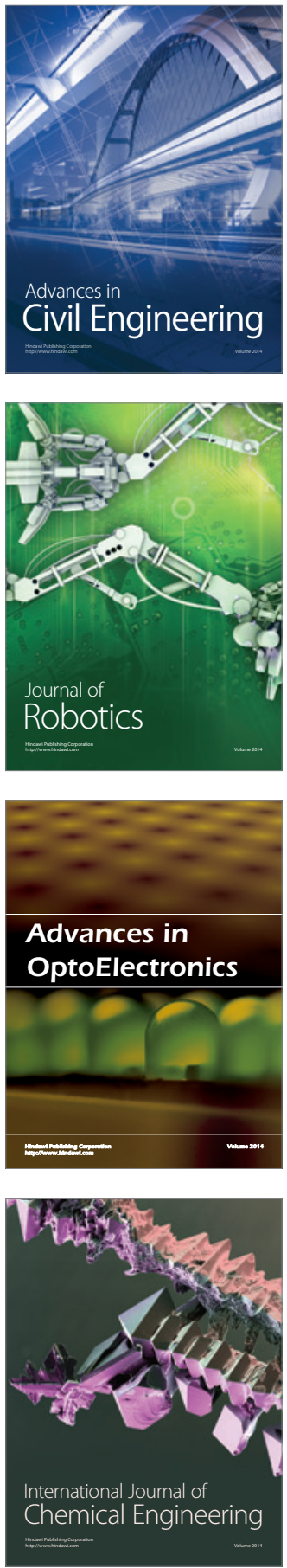

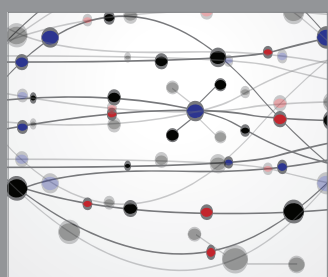

The Scientific World Journal

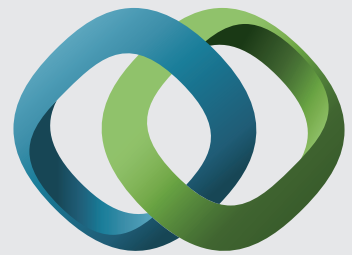

\section{Hindawi}

Submit your manuscripts at

http://www.hindawi.com
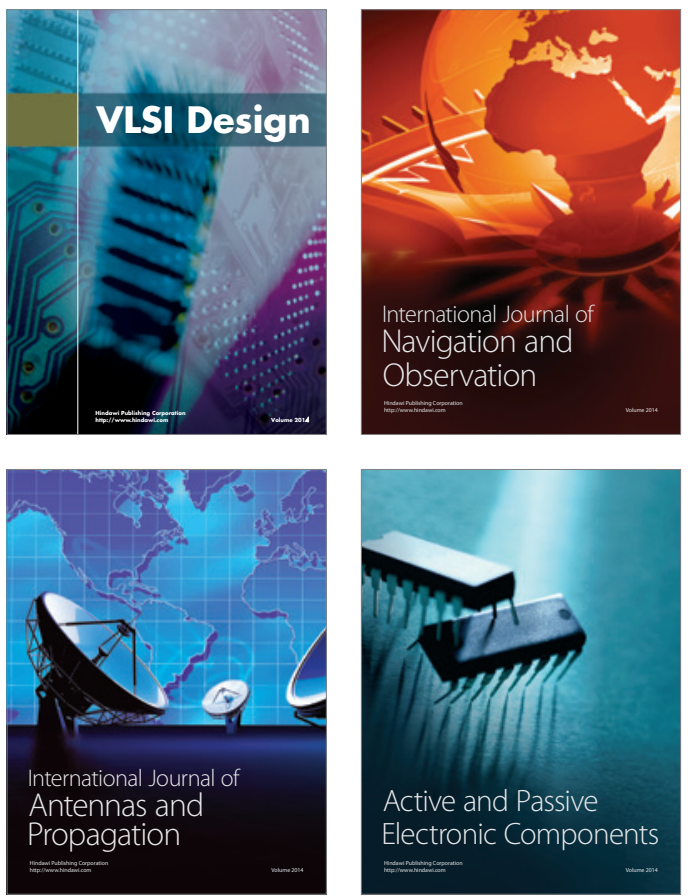
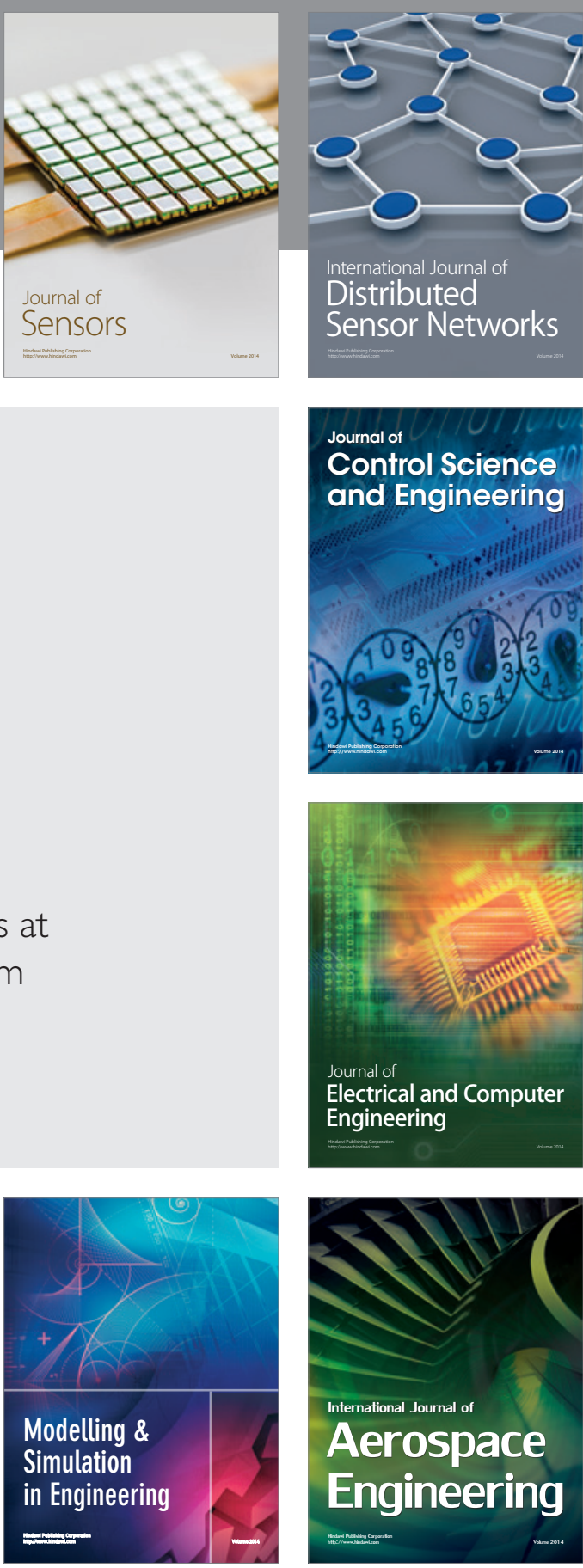

International Journal of

Distributed

Sensor Networks

Journal of

Control Science

and Engineering
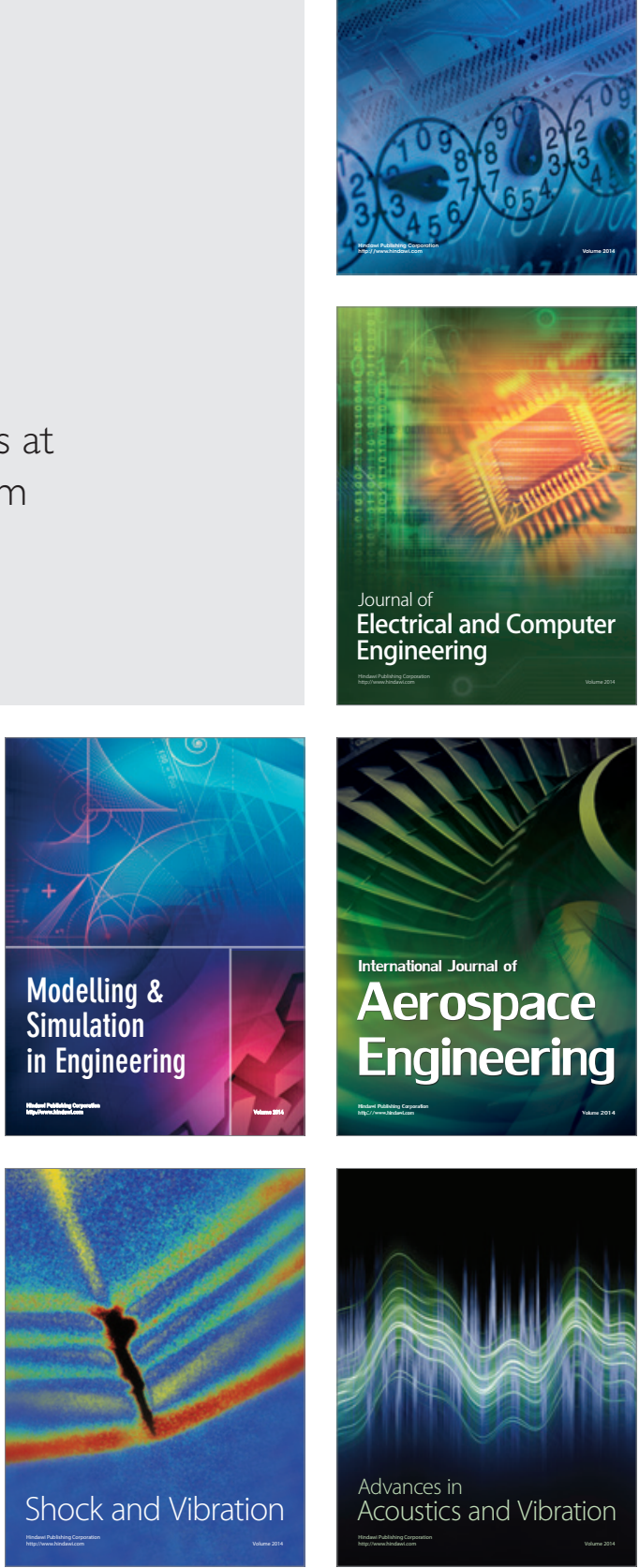